13 Richard, J. Stevenson (Corresponding author), Department of Psychology, Macquarie

14 University, NSW2109 Australia, email dick.stevenson@mq.edu.au

15 Trevor, I. Case, Department of Psychology, Macquarie University, NSW2109 Australia,

16 email trevor.case@mq.edu.au

17 Megan J. Oaten, School of Applied Psychology, Griffith University, QLD4215, Australia,

18 email m.oaten@griffiths.edu.au

19 Lorenzo Stafford, Department of Psychology, University of Portsmouth, PO12UP, UK, email 20 lorenzo.stafford@port.ac.uk

21 Supreet Saluja, Department of Psychology, Macquarie University, NSW2109 Australia, 22 email supreet.saluja@mq.edu.au

The authors would like to thank Dr Betty Repacholi for her comments on earlier

\section{A Proximal Perspective on Disgust}

\author{
Macquarie University \\ Megan J. Oaten \\ Griffith University \\ Lorenzo Stafford \\ Portsmouth University \\ Supreet Saluja \\ Macquarie University
}


Abstract

The functional basis of disgust in disease-avoidance is widely accepted, however

28 there is disagreement over what disgust is. This is a significant problem, as basic questions

29 about disgust require knowing if single/multiple forms/processes exist. We address this issue

30 with a new model with one form of disgust generated by multiple processes: (1) Pure disgust

31 experienced during gastrointestinal-illness; (2) Somatosensory disgust, elicited by specific

32 cues that activate the pure disgust state. (3) Anticipatory disgust, elicited by associations

33 between distance cues for (2) and requiring threat evaluation. (4) Simulated disgusts, elicited

34 by imagining (2\&3) and frequently involving other emotions. Different contamination

35 processes interlink (1-4). The implications of our model for fundamental questions about

36 disgust (e.g., emotion status; continuation into animals) are examined.

37

38 Keywords: disgust, emotion, gustation, olfaction, pain, state, somatosensation 


\section{Introduction}

One of Tinbergen's most enduring contributions to the life sciences has been to identify the four basic questions we should ask about any behavior (Tinbergen, 1963). These questions move from proximal causation, to development, and then to evolution and function - ultimate causation. Disgust researchers have been very successful at addressing issues of ultimate causation, with broad agreement that disgust functions to facilitate disease avoidance (e.g., Curtis \& Biran, 2001; Fleischmann \& Fessler, 2011; Marzillier \& Davey, 2004; Oaten, Stevenson \& Case, 2009; Rozin, Haidt \& McCauley, 2016; Tybur et al., 2013). This functional perspective is now well supported empirically and the aim of this manuscript is not to critique it, but rather to focus on Tinbergen's first two questions. These have unfortunately garnered far less attention and so there is much disagreement over what disgust is, most notably as to whether there is one or multiple types of disgust, or one or multiple forms of process to generate a common disgust state (e.g., Chapman \& Anderson, 2013; Marzillier \& Davey, 2004; Olatunji et al., 2008; Rozin \& Fallon, 1987; Simpson et al., 2006; Tybur et al., 2009). This is a major conceptual problem because several important questions about disgust cannot be effectively addressed without some idea of the answer. One such question concerns disgust's status as an emotion, with one influential theory cleaving disgust in two, with one part as an emotion and the other not (Rozin \& Fallon, 1987). Beyond this there are several other important questions concerning disgust's developmental trajectory, its neural basis and its continuity into animals, all of which depend upon knowing if there is one disgust or many. In this manuscript we start by demonstrating that there are currently few clear answers to what disgust is. The remainder focuses on our answer to this question, and its broader implications for understanding disgust. 
What is disgust?

There have been two main approaches to the what question. The first has categorised 70 cues that elicit disgust (e.g., Angyal, 1941; Curtis \& Biran, 2001; Olatunji et al., 2008; Rozin 71 \& Fallon, 1987; Tybur et al., 2009). This approach is closely allied to the question of 72 function, which has either driven or accompanied categorisation. Currently, there are three elicitor categorisation models. The oldest, developed by 74 Rozin and colleagues (Rozin \& Fallon, 1987; Rozin et al., 2016), divides disgust into five 75 domains each with its own functional basis: (a) distaste covering oral responses to bitter and 76 sour tastants (function: protect body); (b) core disgust, for preventing oral incorporation of 77 body products (e.g., feces), certain foods (e.g., rotten) and certain animals (e.g., maggots; 78 function: protect body and soul); (c) animal reminder disgust, which serves to remind us of our animal origins and hence our mortality (e.g., mangled body; function protect body and 80 soul); (d) interpersonal contamination (e.g., avoiding sick people; function, protect body, 81 soul, and social order); and (e) sociomoral disgust (e.g., defrauding a helpless person: 82 function, protect social order).

83 There have been several attempts to validate these categories. Developmentally, there 84 is support for the early presence of distaste relative to the other disgusts (e.g., Ganchrow, 85 Steiner \& Daher, 1983; Steiner, 1979). Individual differences in distaste are related to 86 disgust sensitivity for elicitors of core and animal reminder disgust, but not to sociomoral 87 disgust (Herz, 2011). Similarly, developmental evidence suggests that core, animal reminder, 88 and sociomoral disgusts occur, in that order, progressively later in development, but whether 89 this means they involve qualitatively different emotional states (i.e., different disgusts) is not 90 established (Stevenson et al., 2010). There seems to be little support for the theoretical 91 underpinning of animal reminder disgust (Kollareth \& Russell, 2016). Interpersonal disgust 
92 may not be uniquely different from the preceding categories, although some recent cross-

93 cultural research suggests it may not induce disgust at all (Han, Kollareth \& Russell, 2016).

94 It has been noted that the sick face associated with illness - and hence avoidance of sick

95 people, which is a type of interpersonal disgust - may differ from the disgust face associated

96 with bad smells or tastes (Widen et al., 2013). While this may suggest a dissociation, it does

97 not cleanly map onto the categories under consideration here (i.e., there is no bad smell and

98 taste domain), nor for that matter does other work examining distinct subtypes of disgust-

99 related facial expression (Rozin, Lowery \& Ebert, 1994). For sociomoral elicitors, this is the

100 most contentious category, with uncertainty as to whether this represents disgust, some

101 metaphorical usage or the involvement of other emotions (Case, Oaten \& Stevenson, 2012;

102 Nabi, 2002; Simpson et al., 2006; Yoder, Widen \& Russell, 2016).

103 Olatunji et al., (2008) have suggested a revised version of Rozin's scheme, with three

104 main categories - core, animal-reminder and contamination disgust. This structuring seems

105 to reflect a consistent pattern of individual differences across cultures (Olatunji et al., 2009).

106 In addition, the categories of distaste and sociomoral disgust are presumably still included,

107 although this is not made explicit. These two categories are not covered in the individual

108 differences measure that forms the basis for the other categories (distaste not being

109 considered as part of the emotion of disgust and because a satisfactory factor solution for

110 sociomoral disgust could not be obtained).

111 Contamination disgust is identified as a specific category in Olatunji et al.'s, (2008)

112 revised scheme. Contamination occurs when there has been contact between a neutral item

113 (e.g., a shoe) and a disgust inducing elicitor (e.g., feces), rendering the contaminated object

114 disgusting (Rozin \& Nemeroff, 1990). To some theorists, contamination is of special

115 significance, with Rozin and Fallon (1987) claiming that the separation between the category

116 of distaste and the other categories of disgust is dependent on the presence of contamination 
117 with the latter but not with the former. Contamination has also been important to functional

118 accounts of this emotion (Oaten et al., 2010), principally because it represents an implicit

119 form of germ theory. Currently, it is unclear what relationship contamination has to disgust,

120 namely whether it is a type of disgust or an accompanying feature. It is also unclear if there

121 are one or multiple forms of contamination process. Some forms may require the

122 development of specific cognitive skills for their emergence (e.g., Rozin, Fallon \&

123 Augustoni-Ziskind, 1985), while others could depend solely upon observing contact (e.g.,

124 Brown \& Harris, 2012).

125 The most recent categorisation-based theory suggests a more circumscribed model

126 composed of three domains (Tybur et al., 2013), with contamination a notable absence. The

127 three-domain model is derived from theoretical considerations of function and from a factor

128 analysis of self-report individual difference data (Tybur, Lieberman \& Griskevicius, 2009).

129 The three disgust domains are pathogen (e.g., feces), sexual (e.g., incest avoidance) and

130 sociomoral. Each domain represents a different function, pertaining respectively to disease

131 avoidance, quality of sexual partners, and quality of other people. The question again here is

132 whether these domains actually reflect different disgusts. There is some evidence for a

133 difference between sexual and pathogen disgusts, based upon greater gender difference on

134 self-report disgust measures for the sexual category, as well as divergent correlations with

135 other self-report measures (Tybur et al., 2009; Olatunji et al., 2012). Evidence for a discrete

136 sociomoral category has the same problems identified earlier for Rozin \& Fallon's (1987)

137 scheme (e.g., see Olatunji et al., 2012), and as we noted above the three-domain model is

138 silent on the nature of contamination.

139 There is a second way in which disgust categorisation has been examined. This

140 involves focussing on the range of emotions that different disgust eliciting cues generate. In

141 common with other emotions and states, disgust may occur in tandem with fear, anger, pity, 
142 sadness, shame and embarrassment. This led Marzillier and Davey (2004; and see Simpson

143 et al., 2006 for a similar idea) to suggest a distinction between simple and complex disgusts -

144 noting that this approach does not accommodate contamination. In this view, there is no

145 intention to think of differences in disgust per se, but rather differences in the number and

146 type of emotions that are elicited. This scheme crudely maps onto those above, in that

147 sociomoral elicitors typically engage a much broader range of emotions, notably anger, than

148 disgusts elicited by say bad smells or tastes. Many animal cues that engender disgust such as

149 rats and spiders, also generate fear (Muris et al., 2008; Tucker \& Bond, 1997; Ware et al.,

150 1994), and thus disgust at animals may be complex in the sense that it involves fear-disgust

151 blends. Similarly, interpersonal disgusts may utilise complex blends including feelings of

152 pity and sadness (Marzillier \& Davey, 2004). This perspective suggests one disgust, but one

153 that involves varying degrees of interaction with other emotions.

154 It is then unclear what disgust is. There is little agreement over how many disgusts

155 there are and no agreement over how contamination fits into this picture. We suggest a new

156 perspective is needed.

\section{Overview}

158 A diagrammatic summary of the model is presented in Figure 1, with four processes

159 that all give rise to the same disgust feeling state (see Table 1 for summary properties and

160 features).

161 Pure disgust

162 An important feature of an emotion or state, which contributes to making it one thing

163 rather than another, is the way it feels. Arguably, the purest feeling state of disgust is

164 generated during gastrointestinal illness. It is characterised by nausea, an aversive bodily

165 sensation localised to the oral-gastric region, which signals gastrointestinal threat and the

166 imminence of its solution in vomiting. This feeling state can be broken down into three 
167 components - its negative affect, its bodily locus and the feeling that vomiting is imminent

168 (i.e., nausea). A further issue of importance here is whether equating gastric sickness to pure

169 disgust means that pure disgust cannot be termed an emotion. Rather than examine this here

170 we discuss the broader question of disgust's status as an emotion at the end of the manuscript.

172 Somatosensory disgust

173 Somatosensory disgust is characterised by a distinct bodily locus, nausea, and

174 negative affect. It is modular (i.e., in considering disgust in animals, different sensory cues

175 could be 'plugged-into' or 'un-plugged from' the brain circuits underpinning disgust) and

176 present early in development. While occurring automatically in response to certain cues - via

177 a dedicated neural link to the same brain circuitry underpinning pure disgust - this process is

178 modulated by bodily threat assessment. Somatosensory disgust occurs: (a) in the mouth, with

179 any of the following senses either alone or in combination - gustation with certain tastants,

180 retronasal (via the posterior nares) olfaction with certain odorants, and via somatosensation

181 with certain textures; (b) orthonasally (via the anterior nares) from smelling certain odorants;

182 and (c) via bodily somatosensation, with certain textures. The somatosensory system is

183 intimately linked to both taste and smell perception, as it assists bodily localisation by

184 binding taste to the tongue and smell to either the mouth (flavor) or nose (sniffing/smelling).

185 Anticipatory disgust

186 Anticipatory disgust first emerges in infancy. During weaning the infant passively

187 learns associations between the sensory components of food - what they see, hear, smell and

188 touch - and its flavor in the mouth. They also passively acquire sensory associations between

189 the visual and auditory appearance of objects, and their smell and feel, an on-going process,

190 which includes experiences during toilet-training, and with other bodily products. 
191 Post-weaning, looking at a food should allow an infant to anticipate what it might be

192 like to eat. Anticipating oral contact with something that signals an unpleasant experience

193 can result in disgust. This occurs via two parallel paths, both of which are necessary for

194 anticipatory disgust to occur. First, via the passively acquired sensory associations that link

195 back to pure disgust (e.g., perception of visual slimy texture automatically activates a

196 representation of slimy texture, which then automatically activates brain areas underpinning

197 pure disgust). Second, via the degree of bodily threat, which is instantiated as a visceral

198 feeling, substituting for the lack of direct physical contact between the elicitor and observer,

199 which only occurs with somatosensory disgust.

200 In some cases, anticipatory disgust cues may overlap with fear-inducing cues, with

201 the latter resulting from dedicated neural detection and response systems for things like

202 spiders and snakes. For example, the slimy visual appearance of snakes may predict how

203 these animals might feel, resulting in anticipatory disgust. As these animals can also be fear

204 provoking, this may combine with the anticipatory disgust to produce a hybrid experience. In

205 other cases, there may be anticipated disgust - such as towards a slimy looking object - and in

206 addition that object may also generate somatosensory disgust via smell. Cues such as feces,

207 urine, and vomit are all examples of combined anticipatory and somatosensory disgusts. A

208 rather different scenario emerges when seeing mutilated bodies. This may involve a far more

209 extensive hybrid of anticipatory disgust (e.g., visual texture cues), empathetic pain, surprise,

210 fear and anxiety.

211 In sum, anticipatory disgusts involve the automatic activation of sensory associations

212 back to pure disgust, a visceral feeling of imminent bodily threat, but without a specific

213 bodily locus. Anticipatory disgust can either occur alone (e.g., a slimy-looking food), in

214 combination with a somatosensory disgust (e.g., seeing and smelling feces), or with other

215 drive states (i.e., empathetic pain), or with one or more emotions (e.g., fear). 
216 Simulated disgust

217 Most people have seen a large range of body forms and products, injuries, dead

218 animals, etc. Even if these have not been seen directly, they may have been viewed in

219 photographs or film. They will also have experienced somatosensory and anticipatory

220 disgusts and will be cogent of the sensory associates of somatosensory disgust (e.g., if

221 something looks slimy it will probably feel that way). These experiences form the basis for

222 simulated disgusts, which occur intentionally, in the physical absence of the inducing object

223 (i.e., you hear, you read, you imagine, etc) and generally with lower levels of bodily threat,

224 as the whole process is a simulation.

225 Simulating disgust is not difficult. We suggest this as much disgust research is based

226 upon answers to self-report questionnaires, which probably involve recalling and/or

227 imagining each scenario. Simulated disgust may induce negative affect, a feeling of bodily

228 threat (viscerality) and nausea. It differs qualitatively from somatosensory disgust as

229 somatosensory stimulation is absent, and from both anticipatory and somatosensory disgust

230 as there is no external eliciting object other than written or spoken words. Consequently,

231 bodily threat should be lower for simulated disgust in comparison to the others.

232 Intentionality is a further differentiating feature. Simulated disgusts generally involve

233 intention to form a simulation, with the process being under conscious control. Anticipatory

234 and somatosensory disgusts are respectively less intentional. A further distinction from

235 anticipatory disgust is the range of emotions that may accompany simulated disgust.

236 Emotions can be generated de novo in mental simulations (e.g., imagining an affect-laden

237 experience is a widely used experimental means of inducing emotion). The resultant

238 emotions such as shame, pity, anger, humiliation and so forth may then co-occur with

239 simulated disgust, making the experience more affectively potent.

240 Contamination 
241 Contamination occurs when a neutral object becomes imbued with the capacity to

242 induce disgust. Three processes can generate contamination, and these act to link pure,

243 somatosensory, anticipatory and simulated disgusts. All three processes are fundamentally

244 connected by a common reliance on associative learning between a disgust state and a neutral

245 object. The first process links pure disgust to somatosensory disgust. The pure disgust

246 experienced during gastrointestinal illness can become associated with a food's flavor

247 (including each individual sensory component), and its smell. Smelling or eating the illness-

248 paired food results in somatosensory disgust, while its appearance - often already linked to its

249 flavor - allows the anticipation of its disgust-inducing properties.

250 The second process links somatosensory and anticipatory disgust to simulated disgust.

251 It occurs when a neutral cue is perceived to come into physical contact with a somatosensory

252 disgust cue. In this case the neutral cue is experienced simultaneously with somatosenory

253 and/or anticipatory disgust. When that disgust-paired neutral cue is later experienced alone,

254 it can generate a form of simulated disgust, in which the somatosensory or anticipatory

255 disgust cue can be recalled/imagined.

256 The third process occurs wholly in the mind. Here, the disgust-eliciting cue is

257 simulated, as is the contact with a neutral target object (e.g., imagine your toothbrush being

258 used to scrub clean a pus filled sore). This allows for violations of causality, as events

259 physically separate in time or space can be imagined contemporaneously, generating

260 phenomena such as backward contamination.

261

Evidence

262 Pure disgust

263 Emotions and states each have their own unique feeling (e.g., Barrett et al., 2007).

264 Disgust has been reported to possess at least three types of feeling, which individually are

265 shared with other emotions and states, but together define the way disgust feels: negative 
266 affect (e.g., Angyal, 1941), nausea/retching (e.g., Rozin, Haidt \& Fincher, 2009; Davey,

267 1994) and viscerality - feeling of imminent or actual bodily contact (e.g., Verstaen et al.,

268 2016). Together, and as others have noted (Royzman \& Sabini, 2001; Royzman, Leeman \&

269 Sabini, 2008; Royzman et al., 2014), this feeling state occurs in its purest form when

270 experiencing gastrointestinal illness, reflecting disgust's probable phylogenetic origin as a

271 threat-detector for ingestible toxins (Chapman \& Anderson, 2013; Darwin, 1872/1998;

272 Glendinning, 2007; Herz, 2011; Rozin, Haidt \& McCauley, 2016; Schienle, Arendasy \&

273 Schwab, 2015).

274 An important aspect of pure disgust is its neural correlates, as these may allow it to be

275 distinguished from non-disgust states. Although the neural correlates of gastrointestinal

276 illness have not been studied a closely related phenomenon has - virtual motion-induced

277 nausea. We suggest it is highly related because nausea resulting from motion-induction,

278 chemotherapy, and illness, can all support conditioned taste aversions (e.g., Arwas, Rolnick

279 \& Lubow, 1989; Bernstein, 1978; De Silva \& Rachman, 1987). This suggests both

280 functional and experiential similarity across these different nausea inducers.

281 The virtual motion procedure has revealed phasic activity in three brain areas that

282 precede increasing reports of nausea - basal ganglia (putamen), locus coeruleus and amygdala

283 (Napadow et al., 2013). Sustained activity in several other brain areas, including the anterior

284 insula, primary and secondary somatosensory cortex, orbitofrontal cortex (OFC), anterior

285 cingulate cortex (ACC), ventral tegmental area (VTA), nucleus accumbens (NA) and

286 ventromedial prefrontal cortex, is associated with increasing nausea (Napadow et al., 2013).

287 We note four things about these activations. First, that OFC, ACC, VTA, NA, anterior insula

288 and amygdala activation are all known to be associated with affect generation (e.g., Carlezon

289 \& Thomas, 2009; Vogt, 2005). Second, that brain areas associated with evaluating bodily

290 threat relevance are active, notably the anterior insula and ACC (e.g., Craig, 2003), and with 
291 direct anterior insula stimulation also generating sensations of nausea (Penfield \& Faulk, 292 1955) and oral-gastric displeasure (Krolak-Salmon et al., 2003). Third, activity in primary

293 and secondary somatosensory cortices, with the former known to underpin somatosensory

294 perception, relating here to increased oesophageal and gastrointestinal activity (e.g., Coen et

295 al, 2007). Fourth, that nausea's direct antecedents involve brain areas involved in: (1) fear

296 and threat-related processing (i.e., amygdala, locus coeruleus); (2) sites known to generate

297 nausea when stimulated in animals (amygdala; Robinson \& Mishkin, 1968); and (3) areas

298 responsible for habitual motor patterns (putamen) that may underpin aversive withdrawal.

299 We suggest that together, this pattern of neural activation is both necessary and sufficient to

300 generate pure disgust.

301 Somatosensory disgust

302 The somatosensory system plays a key role in anchoring gustatory, olfactory and of

303 course tactile disgust to specific bodily locations, generating a located bodily feel. For

304 olfaction, somatosensory cues may dictate whether an odor is perceived as coming from

305 inside (flavor) or outside (smell) the body (e.g., Green, 2002; von Bekesy, 1964). For

306 gustation, somatosensation underpins binding of taste sensation to the tongue (e.g., Green,

307 2002; Todrank \& Bartoshuk, 1991). In general, tactile sensations are detected by

308 mechanoreceptors in the skin (Guinard \& Mazzucchelli, 1996) and feed information to the

309 primary and secondary somatosensory cortex, and to the posterior insula and anterior

310 cingulate cortex (e.g., Case et al., 2016). These brain areas are organised into two processing

311 streams, one dealing with sensory feel and location (especially primary somatosensory

312 cortex), and the other with affective reaction (Morton, Sandhu \& Jones, 2016).

313 We suggested that the gustatory, olfactory and tactile sensations that evoke disgust do

314 so because there are dedicated neural pathways linking their detection to the same brain sites

315 active during pure disgust (see Mzrahi, 2018, for a related proposal). There have been no 
316 specific investigations of this hypothesis, although it is already clear that there are overlaps

317 between brain areas active during gustatory and olfactory somatosensory disgust - OFC,

318 amygdala, anterior cingulate cortex, anterior insular, basal ganglia, primary and secondary

319 somatosensory cortices (Haase, Cerf-Ducastel \& Murphy, 2009; Rolls, Kringelbach \& de

320 Araujo, 2003; Seubert et al., 2010; Small et al., 2003; Wicker et al., 2003; Zald, Hagen \&

321 Pardo, 2002) and the brain areas identified earlier associated with nausea, which we labelled

322 as pure disgust.

323 The main evidence base so far is limited to showing a consistent mapping between

324 perceiving particular stimuli and demonstrating negative affect. In neonates, bitter and sour

325 tastants evoke a facial expression that is readily recognised by adults as indicating

326 dislike/disgust (e.g., Ganchrow, Steiner \& Daher, 1983). This expression also shares

327 substantial similarity to that observed in infant and adult great apes, when exposed to the

328 same stimuli (Steiner et al., 2001). In adult humans, sampling bitter and sour tastants, and

329 concentrated salts (and sweeteners), can yield a similar facial expression (Bredie, Tan \&

330 Wendin, 2014; Weiland, Ellgring \& Macht, 2010). The presence of this reaction to bitter and

331 sour tastants in neonates, and in many primates, suggests these responses arise from a

332 dedicated neural link between receptors and brain areas responsible for generating pure

333 disgust.

334 Functionally, bitter tastes are indicative of plant-based toxins. In rats, there is a

335 substantial correlation between a chemicals $\mathrm{LD}_{50}$ value and the degree of neural activity it

336 evokes in primary taste processing areas. This suggests that the more bitter it is (i.e., greater

337 neural activity) the more toxic it is (Scott \& Mark, 1987). Sour tastants are associated with

338 microbial decay. For extremely high concentration tastants, their ingestion may be harmful

339 (e.g., hypernatremia). 
$340 \quad$ For olfaction, the dominant view (Engen, 1988; Moncrieff, 1966; Rozin, Haidt \&

341 McCauley, 2016) has been that hedonic reactions are mainly learned. However, there are

342 now several reasons to challenge this view. First, certain vertebrates rely on olfactory-based

343 defences (e.g., skunks, common tree snakes, hoatzins, opossums, vultures). Most of these

344 smell of decay (e.g., opossums, skunks), feces (e.g., tree snakes, hoatzins) or vomit (e.g.,

345 vultures). As humans also find these smells repulsive, this would suggest that there are

346 certain classes of odorant that smell foul to other vertebrates. It would be a risky strategy to

347 rely upon a chemical defence if it were of uncertain effectiveness, and such effectiveness

348 presumably relies upon the ability to repel all potential predators. This suggests that some

349 odorants may be repulsive by virtue of their chemical features mimicking odorants that repel

350 primarily because they signal disease-causing agents (i.e., decay, feces).

A second line of evidence comes from studies linking the structural features of

352 odorants to human hedonic reactions. Khan et al., (2007) found that indicators of small

353 molecular size are predictive of less pleasant smells, a finding that has now been replicated

354 several times (e.g., Haddad et al., 2010; Poncelet et al., 2010). These smaller molecules are

355 not only liked less than larger more complex ones (Kermen et al., 2011) but they are also

356 characterised by particular classes of chemical structure, notably indoles, amines and sulphur

357 containing compounds like thiols (Zarzo, 2011). These types of molecule are often the end

358 product of organic decay processes (Keller et al., 2017; Zarzo, 2011), and interestingly thiols

359 are found in abundance in the foul secretion of skunks - the only vertebrate chemical defence

360 agent to be analysed in detail (Wennig et al., 2010).

$361 \quad$ Humans and other primates are especially sensitive to thiols and indoles, relative to

362 other comparable molecular classes. It has been suggested that this is because they are

363 characteristic markers of decay (Laska et al., 2007; Kamiya \& Ose, 1984) as well as being

364 volatile constituents of feces (Chappuis et al., 2015). That certain structural features of an 
365 odorant predict its likely hedonic reaction - including in children (Poncelet et al., 2010) -

366 would seem to favor the idea that the olfactory system, like the gustatory system, has

367 dedicated neural links that result in negative affect in response to certain chemicals. This

368 conclusion is also consistent with the finding that human neonates tend to respond to decay

369 odors (fishy/rotten) with disgust-like facial expressions (Steiner, 1979; Soussignan et al.,

370 1997) and adults respond faster to unpleasant odorants such as indole (Bensafi et al., 2002).

371 The idea of dedicated neural links sub-serving affective responses to certain tactile

372 stimuli, while plausible, has not been explored. Adults and children find similar tactile

373 sensations in the mouth and on the body surface, disgusting (Skolnick, 2013; Boquin et al.,

374 2014). In the mouth, slimy sensations evoke disgust, and people link such sensory qualities

375 to decay and bad smells (Martins \& Pliner, 2006). Child 'picky eaters' find slimy foods in

376 their mouth particularly disgusting and react in the same way when just handling them (e.g.,

377 Nederkoon et al., 2015). These children are also more likely to gag when asked to sample a

378 food they reportedly dislike and also evidence more aversive responses to bodily tactile

379 stimuli (e.g., touching slime) than non-picky eaters (Coulthard \& Jahota, 2016). Studies of

380 tactile responses to areas other than the mouth have been limited to adults and suggest that

381 sensory characteristics associated with microbial decay (i.e., slimy, sticky, gooey) are the

382 most effective stimuli at inducing tactile-driven disgust (e.g., Oum et al., 2011).

383 There is little data as yet to indicate whether tactile disgust cues emerge early in

384 development. However, during toilet training, it has been noted that one of the key drivers of

385 toileting readiness is when children (aged around 18M) manifest a strong dislike for the

386 slimy/gooey feeling of being wet or soiled (Kaerts et al., 2012; Yeager et al., 1999). It is also

387 unclear whether there is any continuity of tactile disgust cues into animals. Tactile cues are

388 important drivers of grooming behavior in many mammals (Greer \& Capecchi, 2002; Sachs,

389 1988). We surveyed people who work and study great apes. Chimpanzees do not like the 
390 feeling of feces on their fur and make great efforts to remove it (Case et al., Submitted).

391 Great apes (and perhaps other mammals too) may possess a disgust-like response to bodily

392 contact with stimuli that have textures that induce disgust in humans.

393 People consume bitter, sour and slimy foods, eat putrid cheese, and contact the bodily

394 products of other people (e.g., sexual encounters, caring for infants; Case, Repacholi \&

395 Stevenson, 2006; de Jong, van Overveld \& Borg, 2013; Rozin, 1976a; Stevenson \&

396 Repacholi, 2005). If these stimuli automatically elicited a full-strength disgust response, then

397 presumably many of these important behaviors would not occur. The fact that they do

398 suggests some form of modulation. We suggest this is substantially based on an evaluation

399 of bodily threat, a notion akin to that proposed by Sparks et al., (2018) in relation to risk

400 assessment and disgust. This evaluation results in either the amplification of disgust (threat)

401 or its reduction (safety; see Herz \& von Clef, 2001, for an example). An analogous and well

402 documented process occurs for pain, with threat evaluation modulating its intensity and

403 unpleasantness (e.g., Jackson, Wang \& Fan, 2014; Wiech et al., 2010).

404 While modulation is clearly relevant to somatosensory disgust - as the examples

405 above suggest - it is not critical for its occurrence, as somatosensory disgusts are threatening

406 by default. The elicitor has already contacted the body (i.e., threat is imminent) and has a

407 propensity to be unpleasant via the dedicated neural link from specific receptors to brain

408 areas subserving this response. In contrast, threat evaluation should be more important for

409 anticipatory disgust, where there is no physical contact and no direct neural link to negative

410 affect. For this reason, we defer a more detailed consideration of threat evaluation until then.

411 In sum, somatosensory disgust is triggered by specific gustatory, olfactory and tactile

412 cues that have dedicated neural links to brain areas that evoke negative affect (and probably

413 nausea too), and it also has a specific bodily location. This disgust response is modulated by

414 a threat evaluation. Functionally, these disgust cues signal toxins and pathogens. Each cue- 
415 response is modular, such that different animal species should have sets of modules attuned

416 to relevant behavioral and environmental risks (e.g., Gorilla's tolerance for bitter and sour

417 tastes because of their folivorous diet [Gustafsson et al., 2014]). Indeed, it is important to

418 note that we currently understand rather little about disgust's continuation into animals, even

419 though this is an issue directly pertinent to understanding process and function in humans.

420 Anticipatory Disgust

421 Anticipatory disgust occurs at the prospect of contacting a physically present

422 somatosensory disgust elicitor. This requires two processes - one mediated via sensory

423 associations with somatosensory disgust that then automatically engage pure disgust and the

424 other via an evaluation of bodily threat. A key issue is the extent to which anticipatory

425 disgust can activate the same qualitative state as somatosensory disgust. Three approaches to 426 this problem are considered.

427 The first is whether when people experience anticipatory disgust they report feeling 428 negative affect, nausea and a visceral feeling of bodily threat. For negative affect there is

429 widespread agreement that viewing disgusting objects is unpleasant (e.g., Kollareth \& 430 Russell, 2016; Rozin et al., 1999; Stevenson et al., 2011; Stevenson et al., 2015). Few studies 431 have used nausea ratings, but those that do find higher ratings for anticipatory disgust stimuli 432 than for control stimuli (Calder et al., 2007; Stevenson et al., 2012). An important caveat 433 here is that almost all of the studies cited in this paragraph used pictorial disgust stimuli.

434 Strictly speaking these cannot be anticipatory disgusts as the stimuli are not physically 435 present. While pictures generate a similar visual state as looking at disgusting objects, they 436 are not real, which may reduce feelings of bodily threat. While no study has measured 437 feelings of bodily threat, pictures/films should be less effective inducers than their real 438 counterparts. 
439 A second approach is neuroimaging, to see if anticipatory disgust activates brain

440 regions that overlap those of pure disgust. There have been several fMRI studies that use

441 pictures of disgust-inducing cues (with the same caveat as noted above). Many pictorial

442 disgust fMRI studies generate activity in the amygdala (e.g., Schienle et al., 2002; 2005;

443 Stark et al., 2003; 2005; Moll et al., 2003), OFC (e.g., Lane et al., 1997; Paradiso et al., 1997;

444 Schafer et al., 2005) and anterior insula (e.g., Wright et al., 2004; Jabbi et al., 2008).

445 However, we could find only one that reported activation in the basal ganglia, and only then

446 when examining correlations with self-reported disgust (Calder et al., 2007). No study

447 reported primary or secondary somatosensory cortical activity, as would be expected. So,

448 there are some similarities to the neural activity pattern characterising pure disgust, but

449 pictures are not as potent a threat to the body as their real equivalent.

450 A third approach is to look to the example of pain. This is important because of the

451 issue of bodily threat, which we suggest is a key component of anticipatory disgust.

452 Anticipated and real pain produce overlapping patterns of neural activity (e.g., Fairhurst et

453 al., 2012; Ogino et al., 2007; Ploghaus et al., 1999), as do anticipated (using pictures - so

454 caveats above apply) and somatosensory disgust (e.g., Jabbi, Bastiaansen \& Keysers, 2008;

455 Wicker et al., 2003). The overlap for both pain and disgust, when contrasting real and

456 anticipated states, occurs in the anterior insular cortex (Jabbi, Bastiaansen \& Keysers, 2008;

457 Singer \& Lamm, 2011; Lamm, Decety \& Singer, 2011; Wicker et al., 2003) - and especially

458 so if there is greater personal bodily threat (e.g., anticipating oneself being injected in the

459 hand vs. viewing someone else being injected; Decety \& Grezes, 2006).

460 We suggest the anterior insula supports bodily threat evaluation. First, it is the neural

461 correlate of visceral body-related feelings (e.g., Craig, 2003). Crucially, this feeling is not

462 associated with a specific bodily location. Rather, specific locations are represented by

463 activity in the primary somatosensory cortex, just as for externally induced pain (Lamm, 
464 Decety \& Singer, 2011). Second, activity in the anterior insula is known to support aversive

465 anticipatory arousal for pain (e.g., Ploghaus et al., 1999; Ogino et al., 2006), which is

466 effectively an evaluation of a stimulus's threat potential to the body. Third, we noted earlier

467 that pain is modulated by threat, with greater threat linked to more pain in both experimental

468 and naturalistic settings (Jackson, Wang \& Fan, 2014). Functional imaging suggests that the

469 neural correlate of pain modulation resides in the anterior insula (Wiech et al., 2010). If there

470 is an imminent threat to the body, the anterior insula integrates relevant information, resulting

471 in a visceral feeling of threat whose intensity reflects its imminence. We also hypothesise

472 that the anterior insula may then act to up (or down) regulate the activity of the brain areas

473 that underpin pure disgust. Notably then, anterior insula lesions should impair a rather

474 specific aspect of disgust - its threat evaluation capacity.

475 The idea that threat or risk estimation is strongly linked to disgust has been made

476 before (e.g., Sparks et al., 2018), as has the idea that threat estimation can be instantiated as a

477 feeling (see Loewenstein et al., 2001). In addition, and as we noted earlier, threat-driven

478 response amplification is seen in pain (above) and in other states (Koteles \& Whitthoft,

479 2017), suggesting by analogy that this type of process could also occur for disgust. However,

480 there have been no direct investigations of whether bodily threat evaluations lawfully affect

481 disgust, although several extant findings suggest this is likely. Habituation should diminish

482 threat, and it certainly diminishes disgust (e.g., Rozin, 2008). The source of an elicitor (e.g.,

483 self vs. other) affects the magnitude of the disgust response, with source reflecting perceived

484 disease threat (e.g., Stevenson \& Repacholi, 2005). Bodily need should also modify threat

485 estimation, so for example, hunger might be expected to lead to less disgust towards food that

486 might otherwise induce disgust (e.g., Hoefling et al., 2009; Sacco, Young \& Hugenberg,

487 2014) and sexual arousal should lead to reductions in disgust towards cues that might

488 normally signal disease (e.g., Stevenson, Case \& Oaten, 2011 ). Health-related anxiety 
increases evaluations of disease threat, and this translates into more intense disgust (e.g., Fan

490 \& Olatunji, 2013). These and other variables (e.g., physical proximity, risk expectation,

491 context) will then act to amplify or dampen the anticipatory disgust response - to the extent

492 that it is felt to be a threat. While threat evaluation can serve to unify this diverse range of

493 moderating variables, it may be too procrustean. The possibility remains that multiple

494 separate mechanisms may serve to up and down regulate disgust - but such an alternate

495 model would come at the cost of parsimony.

496 We suggested that somatosensory disgust had dedicated neural links between cue

497 detectors and brain areas sub-serving affective response. In contrast, anticipatory disgusts are

498 passively learned sensory associations that emerge during development and which then

499 automatically link a visual or auditory cue with a somatosensory disgust cue. The first

500 anticipatory disgusts are probably acquired during weaning (between $6 \mathrm{M}$ and $18 \mathrm{M}$ ), when the

501 infant is first exposed to a range of liquid then solid foods, varying in physical appearance,

502 texture, taste and smell, allowing them to learn the sensory properties and correspondences of

503 new foods. Part of this learning involves forming associations between the external and

504 internal attributes of flavor: (1) the appearance of food, its sound, and texture to touch, with

505 its oral texture; (2) appearance of food with its flavor; and (3) the flavor with its orthonasal

506 smell. This then allows the infant to anticipate that a particular food will have an unpleasant

507 texture or flavor in the mouth, by simply looking at, touching and smelling it. Thus, viewing

508 the food, can automatically generate a prediction of whether it will taste disgusting based on

509 its sensory correlates. We suggest this mental prediction is represented as a feeling of disgust

510 rather than that of (or in addition to) the food's flavor. There are three reasons for this. First,

511 as the person is actively perceiving - for example looking at the somatosensory disgust cue -

512 this is likely to make forming a mental image of its flavor, difficult. Second, mental imagery

513 for taste, smell and flavor is poor (Stevenson \& Case, 2005). Third, as the link between the 
514 visual/auditory cues and the somatosensory disgust cue is passively learned, it may be

515 activated in a similarly passive manner, and so the link back to disgust may be rapid and

516 unintentional - automatic. While it is important to stress that this developmental perspective

517 has not been tested, it seems uncontroversial to suggest that the link between a food's

518 appearance and its probable flavor results from prior learning and that the first opportunity

519 for this occurs during weaning (Stevenson, 2009), but the nature of the resulting

520 representation is less certain.

521 One probable manifestation of food-related anticipatory disgust in children (and in

522 adults) is the avoidance of unfamiliar foods - neophobia. If food neophobia and anticipatory

523 disgust are much the same, there should be an association between the degree of neophobia

524 that an adult or child displays and their disgust sensitivity. Such associations, of moderate

525 size, have been reported (Bjorklund \& Hursti, 2004; Nordin et al., 2004; Al-Shawaf et al.,

526 2015). A further and important observation is that when people are asked why they will not

527 consume an unfamiliar food they say: (1) it will be disgusting (e.g., Martins \& Pliner, 2005);

528 and (2) they identify sensory properties, notably textural ones like sliminess, associated with

529 somatosensory disgust (e.g., Boquin et al., 2014). This is especially so in picky eaters, who

530 demonstrate a high degree of neophobia and indicate that many foods will invoke disgust

531 from their smell, taste or tactile qualities (Nederkoon et al., 2015; Russell \& Worsley, 2013).

532 A further issue is the continuity of anticipatory disgust into animals. As we noted

533 earlier, many mammals avoid bitter or sour tastants and display facial expressions that in

534 some cases are reminiscent of human responses to such tastes (e.g., Steiner et al., 2001). It

535 has often been assumed that this is likely the full extent of the overlap between humans and

536 animals, but we suggested earlier that the link is more substantial and may include certain

537 odorants (for which there is already some evidence; Laska et al., 2007), as well as certain

538 tactile stimuli. Here, we suggest a further extension to include what is presumably a common 
539 form of anticipatory disgust - neophobia. Neophobia is evident in primates, especially

540 chimpanzees (e.g., Gustafsson et al., 2014), and rodents (e.g., Rozin, 1976b), but whether it

541 conforms to the type of anticipatory disgust envisaged here is not known.

542 Using the same basic process of sensory association, it is possible to see how body

543 products and decay-related stimuli can contribute to and/or engender an anticipatory disgust

544 response. Three mechanisms are at work. First, body products and decaying organic matter

545 often emit chemicals that can induce somatosensory disgust when smelled (Laska et al.,

546 2007; Kamiya \& Ose, 1984). Second, body products and decaying organic matter have

547 physical properties that directly induce somatosensory disgust if they are touched or trodden

548 in, most notably a slimy feel (Oum et al., 2011; Skolnick , 2013). Third, visual examination

549 or auditory cues can reveal information about texture (e.g., in other domains see De Wijk et

550 al., 2004; Zampini \& Spence, 2004) that should anticipate somatosensory disgust. Toilet

551 training affords the child many opportunities to learn cross-modal sensory associations

552 between the sounds (e.g., defecation), appearance (e.g., visual texture/color), tactile

553 properties (e.g., skin of the anal-genital region and from hand contact) and smell of feces.

554 The resulting combination of anticipatory and somatosensory disgust - at the sight and smell

555 of things like feces - should then evoke a more potent disgust response (i.e., additivity).

556 There are a number of disgust elicitors identified in the literature (e.g., Tolin et al.,

557 1997) that are also known to be the target of specific fears (i.e., phobias), notably animals

558 such as snakes, rodents and spiders (e.g., Sawchuk et al., 2002), and blood, injury, and

559 mutilation phobias (e.g., Bienvenu \& Eaton, 1998; Page, 1994). Perhaps not surprisingly, the

560 tendency to develop all of these forms of specific phobias is substantially heritable (Kendler

561 et al., 2001; Van Houtem et al., 2013). This may reflect a graded tendency for a near

562 universal fear response to these types of stimuli, based upon dedicated neural detection and

563 response systems - a parallel perhaps to somatosensory disgusts. As indicated earlier, not 
564 only are these stimuli fear provoking but they may also have visual characteristics that 565 anticipate disgust on contact (i.e., visual texture indicative of sliminess - exposed intestines

566 or snake scales), so there may be fear induced by sight of the animal or injury, combined with

567 anticipatory disgust. The presence then of fear, anxiety (and empathetic pain in the case of

568 injury) should increase the experienced negative affect well-beyond that generated by

569 anticipatory disgust alone (see, Kupfer, 2018; Shenhav \& Mendes, 2014). Moreover, the

570 presence of fear and anxiety would also increase feelings of bodily threat, which would then

571 lead to an amplification of anticipatory disgust.

572 In sum, anticipatory disgust occurs when: (1) a sensory correlate of a physically

573 present somatosensory disgust cue is perceived, which then automatically activates brain

574 regions sub-serving pure disgust; and (2) the somatosensory disgust cue is judged to be an

575 imminent threat to the body. Anticipatory disgusts are dependent on sensory cross-modal

576 learning for their emergence during development, unlike somatosensory disgusts, which are

577 based upon dedicated neural links between receptor and brain areas sub-serving negative

578 affect and disgust. Experientially, anticipatory disgusts should involve the same set of

579 qualitative features as somatosensory disgust, namely negative affect, viscerality and nausea.

580 Anticipatory disgusts like anticipatory pain lack a discrete bodily locus, and so both of these

581 states should be reliant on bodily threat perception mediated by the anterior insula. Anterior

582 insula activity should also serve to up or down regulate brain regions associated with the pure

583 disgust response. The recruitment of other negative emotions and the presence of

584 somatosensory disgust, may all serve to increase affective potency.

585 Simulated disgust

586 Mental simulation is a ubiquitous aspect of human cognition, involving recreations of

587 motor actions, sensory and emotional states (Hesslow, 2002). Simulated disgust is an

588 intentional act of the imagination driven either by self or other (e.g., thinking, reading or 
589 hearing about disgust) and is widely used in contemporary disgust research (i.e.,

590 questionnaires, vignettes). It involves the person imagining a somatosensory or an

591 anticipatory disgust cue. It may also involve imagining being disgusted or showing disgust

592 divorced from any particular eliciting cue (e.g., demonstrating disgust for someone in a

593 daydream). Simulated disgust is distinct from anticipated disgust, in three ways. First, no

594 somatosensory disgust elicitor is required for its activation. Second, there can be no threat of

595 contact with the disgust elicitor, as there is no physical elicitor present, which may reduce the

596 magnitude of anterior insula activation (i.e., minimal bodily threat). Third, for anticipatory

597 disgust, mental content is feeling disgust and what is perceived (e.g., seeing dog feces), while

598 for simulated disgust mental content is feeling disgust and what is imagined.

599 While simulated disgusts are likely then to be less potent than anticipatory and

600 somatosensory disgusts, we suggest that it may be rare to experience this state on its own.

601 Fear, sadness, pity, shame and anger, can each be generated solely from acts of the

602 imagination and these can be as potent as those resulting from real situations (Oatley, 2016) -

603 hence the widespread use of imagination as an experimental emotion induction technique

604 (e.g., Gerrards-Hesse, Spies \& Hesse, 1994). This is important, because these emotions may

605 often accompany simulated disgust (e.g., moral violations, prejudice, horror; Cottrell \&

606 Neuberg, 2005; Russell \& Giner-Sorolla, 2013; Ottaviani et al., 2013). While the presence of

607 these emotions along with simulated disgust should inflate the degree of negative affect - this

608 feeling being common to them all - it should not affect reports of viscerality or nausea, which

609 are particular to disgust, unless these other emotions somehow generate a sense of bodily

610 threat.

611 Although we know of no direct data, we suggest that simulated disgust in adults is

612 common. Adults appear to have little difficulty in either recalling disgusting events or in

613 simulating how disgusting something would be (e.g., Haidt, McCauley \& Rozin, 1994). 
614 Moreover, the process of simulation allows disgust to be extended into situations that are

615 infrequently encountered. Two examples should suffice. First, having dirty underwear, not

616 washing hands after using the toilet, and sleeping on soiled bedding are things that can be

617 readily imagined about someone, but that are less likely to be observed. Second, one is more

618 likely to hear about the sexual exploits of another person than to directly witness them.

619 Finally, the flexibility of this process lends itself both to humour (e.g., Hemenover \&

620 Schimmack, 2007), as simulated disgust offers minimal threat, and also to story transmission

621 via its emotionally arousing nature (Heath, Bell \& Sternberg, 2001).

622 Contamination

623 Contamination occurs when a neutral object becomes imbued with the capacity to

624 induce disgust. We suggested three processes that can generate contamination, which relate

625 to the types of disgust outlined in our model. The first is conditioned taste aversions, in

626 which non-disgust inducing stimuli - almost always a food - becomes associated with a

627 gastrointestinal disturbance generating pure disgust - nausea, negative affect and viscerality.

628 Animal studies indicate that oral based taste (Garcia \& Koelling, 1966), retronasal odor (e.g.,

629 Bouton, Dunlap \& Swartzentruber, 1987), oral texture (e.g., Ramirez, 1992) or their

630 respective combinations - and in addition the sniffed smell of an oral based flavor (e.g.,

631 Capaldi, Hunter \& Privitera, 2004) - can all serve as associates of pure disgust. Similar

632 findings are observed in humans, with aversions found to the specific taste, smell (orthonasal

633 and retronasal) and texture of foods (De Silva \& Rachman, 1987; Logue, Ophir \& Strauss,

634 1981).

635 Somatosensory disgust may be most strongly associated with the mouth as this

636 location combines all of the eliciting senses of taste, smell and touch, relative to olfaction or

637 touch alone - as well as the greatest threat to bodily integrity. Conditioned taste aversion

638 learning seems to follow this same ordering of being most potently linked to flavor cues in 
639 the mouth and then to the smell of food. Once an association has been formed, the human

640 literature suggests that the linked food comes to act as: (1) a somatosensory disgust (i.e., to its

641 smell, taste, texture); (2) an anticipatory disgust, presumably based on pre-existing sensory

642 associations, with its sight sufficient to induce feelings of nausea, negative affect and

643 viscerality; and (3) as a simulated disgust (i.e., imagining it produces revulsion; De Silva \&

644 Rachman, 1987; Logue, Ophir \& Strauss, 1981).

645 The second contamination process involves the direct observation of an affectively

646 neutral object coming into physical contact with a somatosensory or anticipatory disgust cue.

647 This has a powerful effect. For example, Rozin, Millman and Nemeroff (1986) had

648 participants watch as they touched a sample of a previously liked fruit juice with what they

649 described as a sterilized cockroach. Immediately after the cockroach was removed,

650 participants judged the juice as undrinkable. Presumably the capacity to visualise and

651 remember the contacting disgust elicitor underpins this contamination effect.

652 A further aspect of Rozin, Millman and Nemeroff's (1986), experiment was the

653 minimal generalisation of disgust to a new juice sample of the same type as the contaminated

654 one. This illustrates the importance of cognitive control over the spread of contamination.

655 Participants were aware that there was no cockroach contact with the new juice sample - in

656 contrast to behaviour observed with conditioned taste aversions, where any example of the

657 aversive food can induce disgust. Where generalization with this second contamination

658 process does occur, it is typically pathological, with contamination rapidly spreading to

659 related objects (Rachman, 2006). Developmentally, direct physical contamination probably

660 emerges after weaning, with the earliest evidence observed in 18-24M infants, with contact

661 between a liked and a disliked food rendering the liked food inedible (e.g., Brown \& Harris,

662 2012). Over time, the range of stimuli (i.e., disgust inducers) that can support physical 
663 contamination grows, moving from direct physical traces (i.e., somatosensory disgust) to

664 anticipatory disgusts (Rozin, Fallon \& Augustoni-Ziskind, 1985).

665 The third contamination process just involves mental simulation with the contaminant

666 and the neutral object both being imagined. People seem readily capable of undertaking

667 simulated contamination, as evidenced by the large number and variety of experimental tasks

668 that require this approach (e.g., Fairbrother, Newth \& Rachman, 2005; Rozin, Markwith \&

669 McCauley, 1994; Riskind \& Maddux, 1994). Mechanistically, it likely involves holding in

670 working memory a representation that explicitly connects the disgust elicitor and the

671 contaminated object. Note how this mental process can potentially allow simulated

672 contamination to violate causality (e.g., thinking that tomorrow a stranger will die in the hotel

673 bed you are going sleeping in today, can render that bed disgusting now; Rozin et al., 1989;

674 and see, Kim \& Kim, 2011).

675

Discussion

676 This manuscript offers a proximal perspective on what disgust is. Fundamentally, we 677 suggest that there is one disgust state with four processes that can generate it (see Table 1).

678 This common disgust state is a set of feelings - negative affect, nausea and viscerality (actual

679 and/or imminent bodily threat). The processes that generate it are primarily distinguished by:

680 (1) the physical presence or absence of an elicitor (absent - pure and simulated disgust;

681 present - somatosensory and anticipatory disgust); (2) the presence or absence of a discrete

682 bodily location (absent - anticipatory and simulated disgust; present - pure and

683 somatosensory disgust); and (3) the degree of threat to the body (in order from generally

684 greatest to least; pure, somatosensory, anticipatory and simulated disgust). The extent to

685 which negative affect, nausea and viscerality are present is especially dependent on bodily

686 threat evaluation, the presence of other emotions and states, and whether multiple disgust

687 eliciting cues are present. 
688 An important feature of disgust is its capacity to make other things, which previously

689 did not evoke a response, disgusting. Three contamination processes are envisaged that

690 directly relate to the disgust processes in our model. These allow the creation of: (1) new

691 somatosensory disgust cues, constrained by their relevance to the gastrointestinal system; (2)

692 new anticipatory disgust cues, following an object's contact with a somatosensory disgust

693 elicitor; and (3) new simulated disgust cues, by imagining contact between a neutral and a

694 disgust eliciting object. Just as there is a transition from cognitively inflexible and automatic,

695 to cognitively flexible and controlled, when moving from pure to simulated disgust

696 processes, the same trend is evident in moving from conditioned taste aversions to simulated

697 contamination processes.

698 Disgust is generally regarded as an emotion (Ortony \& Turner, 1990), which is

699 defined here as an object-orientated intentional affective state. Disgust is also widely

700 regarded as a basic emotion, possessing a defined set of properties (Ekman, 1999).

701 Determining what is included as an 'emotion' is a hard problem (Scarantino, 2012), with

702 much argument over boundary conditions (e.g., Craig, 2003; is pain an emotion?). Whether

703 disgust should be categorised among the emotions like fear and anger has also been debated

704 (e.g., Royzman \& Sabini, 2001). As we noted earlier, Rozin and Fallon, (1987) argued that

705 everything beyond distaste (i.e., reactions to bitter and sour) constitutes disgust and is an

706 emotion. In contrast, few emotion researchers have regarded pain as a basic emotion (Ortony

$707 \&$ Turner, 1990), even though it has a distinct facial expression (Williams, 2002), the

708 capacity to experience it is present from birth, and it is clearly affect laden. Perhaps this is

709 because pain is very closely allied to somatosensory perception and is linked to a specific

710 bodily location. This description sounds very much like pure and somatosensory disgust.

711 Both have distinct bodily locations, either in or on the body (Fessler \& Haley, 2006). 
712 Avoiding terminology, we could say that pain and pure and somatosensory disgust are

713 taxonomically more alike, than these last-mentioned forms of disgust and the basic emotions.

714 A further issue is the 'emotion' status of anticipatory and simulated disgust. If pure

715 and somatosensory disgust are not emotions, then perhaps anticipatory or simulated disgust

716 cannot be either, because we can anticipate and simulate pain but this is still not thought of as

717 an emotion. Izard (2007) has suggested the existence of emotion-cognition complexes to

718 account for the array of interactions that routinely occur between basic emotions and

719 cognitions in adults. One could extend this idea to consider new forms of interaction

720 between threat-based feelings, states such as pain and disgust, and other emotions. Thus

721 alone, pain and disgust may be more state-like, but perhaps they can achieve a more emotion-

722 like status when they interact with threat-based feelings and emotions.

723 Functionally disgust serves to keep us distant from disease (e.g., Curtis \& Biran,

724 2001; Fleischmann \& Fessler, 2011; Marzillier \& Davey, 2004; Oaten, Stevenson \& Case,

725 2009; Rozin, Haidt \& McCauley, 2016; Tybur et al., 2013). For pure and somatosensory

726 disgust, this link is clear. Pure disgust is envisaged to be synonymous with the feeling state

727 of gastrointestinal illness and somatosensory disgust cues are linked to toxins, bacterial

728 degradation products and microbe-friendly environments. For anticipatory disgust elicitors,

729 much the same holds, as these are sensory associates of somatosensory disgust elicitors. For

730 simulated disgust it becomes harder to tie this back to disease avoidance, making it

731 functionally more flexible. For example, people can be shaped to think of certain things in a

732 way that draws attention to their disgust-related properties - or equally that does not. On

733 some occasions this may align with disease avoidance (e.g., poor hygiene), but it could

734 equally reflect other social forces that have no direct connection to disease (e.g.,

735 manipulating out-group fear). 
A significant area of contention in the literature has been the issue of moral disgust,

737

738

739

740

741

742

743

744

745

746

747

748

749

750

751

752

753

754

755

756

757

758

759

760

and most notably whether it involves disgust at all (e.g., Case, Oaten \& Stevenson, 2012;

Nabi, 2002; Simpson et al., 2006; Yoder, Widen \& Russell, 2016). The process model we propose is silent on whether certain forms of immoral behavior can induce disgust. This is because the model does not rely on specifying elicitor types - beyond those involved in somatosensory disgust - but rather focusses on process. Thus, if the requisite process is engaged, and in this case it would most likely be simulated disgust (i.e., hearing about a person's behavior), then disgust should be experienced.

As outlined earlier, a considerable amount of theorising and research has revolved around grouping elicitors into domains and then comparing them to discern their different properties. We suggest this line of enquiry is problematic. Setting aside the multiple forms of grouping and the ensuing lack of agreement over which might be correct, the more fundamental 'carving at the joints' may not always align with elicitor types, but rather with the cognitive processes that give rise to the disgust response, and whether that disgust response is common across processes. For some reason, possibly because of the focus on function, the study of elicitor groupings seems to have dominated thinking about disgust in a way that has not occurred for most other emotions and states.

Elicitor categories seem to be most meaningful for the somatosensory disgusts, arguably because of their modularity (e.g., see Peng et al., 2015). For example, bitter taste receptors are of lesser value to carnivores or folivorous animals, which consume, respectively, either none or very large quantities of secondary plant products. Similarly, olfactory signals of decay are of value to animals that consume rotting flesh, just as fecal odors are of high value for avoiding predators - but in each case with differing valence. Aversion to slimy feces-filled innards is of little use to a carnivore with its head inside the guts of its prey, but of great use to a social animal that needs to avoid its conspecifics feces. 
761 Somatosensory disgust cues may then represent a coalition of disease-avoidant cues that are

762 each 'plugged in' to pure disgust, with the repertoire dependent on ecological need. Beyond

763 somatosensory disgusts, we suggest that a basic form of anticipatory disgust - neophobia -

764 may be present in mice, rats and chimpanzees, but how extensive other forms of anticipatory

765 disgust are, remains to be examined (but see, Sarabian, Ngoubangoye \& Macintosh, 2017).

766 We made three claims about the neural basis of disgust. First, that the brain state

767 observed during gastrointestinal illness reflects the purest neural correlate of the common felt

768 experience of disgust - albeit based on induced virtual motion sickness. Second, that the

769 primary somatosensory cortex is active for pure and somatosensory disgust, giving these

770 states a specific bodily location, something not expected for anticipatory and simulated

771 disgust. Third, while pure and somatosensory disgust represent actualised bodily threats, and

772 so should be associated with activity in the anterior insula (Ploghaus et al., 1999; Ogino et al.,

773 2006), the potential degree of bodily threat should dictate the degree of anterior insula

774 activity for anticipatory and simulated disgusts. In turn, damage to these brain areas should

775 produce particular forms of deficit. Lesions or drugs affecting the neural basis of nausea -

776 amygdala, putamen, locus coeruleus (Napadow et al., 2013) - should impair the capacity to

777 experience all forms of disgust, by diminishing its unique feel relative to other states and

778 emotions. Lesions that affect somatosensory processing (i.e., parietal lobe) should reduce the

779 sense of viscerality and hence the threat-value of somatosensory disgusts. Such lesions

780 should have less impact on anticipatory and simulated disgust, which rely for bodily threat

781 evaluation on the anterior insula. Lesions affecting the anterior insula should affect threat-

782 evaluation and impair disgust amplification, notably for anticipatory and simulated disgust.

783 Our model also has implications for the development of disgust. From the

784 perspective of developmental order, we suggest that: (1) the brain circuitry to support pure

785 disgust is present at birth; (2) somatosensory disgusts appear at birth, or soon after; (3) the 
786 first anticipatory disgusts emerge at around $18 \mathrm{M}$ connected with weaning and toilet training;

787 and (4) simulated disgust emerges last, dependent both upon the maturation of the cognitive

788 processes necessary to support imagination and a body of disgust-experience to draw upon.

789 The capacity for each type of contamination should emerge in line with this scheme. Key

790 developmental processes should involve learning sensory associations and the formation of

791 threat evaluation feelings.

792 In conclusion, we suggest that our model offers a new and more productive

793 framework to approach important proximal questions about disgust's development, its neural

794 basis, its continuity into animals, and its status as an emotion.

795

796 
798 Al-Shawaf, L., Lewis, D. M., Alley, T. R., \& Buss, D. M. (2015). Mating strategy, disgust, 799 and food neophobia. Appetite, 85, 30-35. doi:10.1016/j.appet.2014.10.029

800 Angyal, A. (1941) Disgust and related aversions. Journal of Abnormal and Social $801 \quad$ Psychology, 36, 393-412. doi:10.1037/h0058254

802 Arwas, S., Rolnick, A., \& Lubow, R. (1989). Conditioned taste aversion in humans using 803 motion-induced sickness as the US. Behaviour Research and Therapy, 27, 295-301. 804 doi:10.1016/0005-7967(89)90049.

805 Barrett, F. L., Mesquita, B., Ochsner, K. N., \& Gross, J. J. (2007). The experience of 806 emotion. Annual Review of Psychology, 58, 373-403.

807 doi:10.1146/annurev.psych.58.110405.085709.

808 Bensafi, M., Rouby, C., Farget, V., Vigouroux, M. \& Holley, A. (2002). Asymmetry of 809 pleasant vs. unpleasant odor processing during affective judgment in humans. Neuroscience Letters, 328, 309-313.

811 Bernstein, I. L. (1978). Learned taste aversions in children receiving chemotherapy. 812 Science, 200, 1302-1303.

813 Bienvenu, O. J., \& Eaton, W. W. (1998). The epidemiology of blood-injection-injury phobia. 814 Psychological Medicine, 28, 1129-1136. doi:10.1017/S0033291798007144

815 Bjorklund, F., \& Hursti, T. J. (2004). A Swedish translation and validation of the disgust 816 scale: A measure of disgust sensitivity. Scandinavian Journal of Psychology, 45, 279817 284. doi:10.1111/j.1467-9450.2004.00406.x

818 Bouton, M. E., Dunlap, C. M., \& Swartzentruber, D. (1987). Potentiation of taste by another 819 taste during compound aversion learning. Animal Learning \& Behavior, 15, 433-438. 820 doi:10.3758/BF03205053. 
821 Boquin, M. M., Moskowitz, H. R., Donovan, S. M., \& Lee, S. (2014). Defining perceptions 822 of picky eating obtained through focus groups and conjoint analysis. Journal of Sensory Studies, 29, 126-138. doi:10.1111/joss.12088.

824 Bredie, W. L., Tan, H. S., \& Wendin, K. (2014). A comparative study on facially expressed 825 emotions in response to basic tastes. Chemosensory Perception, 7, 1-9. doi:10.1007/s12078-014-9163-6.

Brown, S. D., \& Harris, G. (2012). A theoretical proposal for a perceptually driven, food828 based disgust that can influence food acceptance during early childhood. International Journal of Child Health and Nutrition, 1, 1-10. doi:10.6000/19294247.2012.01.01.01.

Calder, A. J., Beaver, J. D., Davis, M. H., van Ditzhuijzen, J., Keane, J., \& Lawrence, A. D. 832 (2007). Disgust sensitivity predicts the insula and pallidal response to pictures of disgusting foods. European Journal of Neuroscience, 25, 3422-2428. doi:10.1111/j.1460-9568.2007.05604.x

Capaldi, E. D., Hunter, M. J., \& Privitera, G. J. (2004). Odor of taste stimuli in conditioned “taste” aversion learning. Behavioural Neuroscience, 118, 1400-1408. doi:10.1037/0735-7044.118.6.1400.

Carlezon, W. A. Jr., \& Thomas, M. J. (2009) Biological substrates of reward and aversion: a nucleus accumbens activity hypothesis. Neuropharmacology, 56, 122-132.

841 Case, T.I., Stevenson, R.J., Byrne, R. \& Hobaiter, C. (Submitted). The animal origins of 842 disgust: reports of basic disgust in great apes.

843 Case, T. I., Oaten, M. J., \& Stevenson, R. J. (2012). Disgust and moral judgment. In: 844 Emotions, imagination, and moral reasoning, (Eds) R. Langdon \& C. Mackenzie [pp. 845 95-218]. Psychology Press. 
846 Case, T.I., Repacholi, B.M. \& Stevenson, R.J. (2006). My baby doesn't smell as bad as your:

847 The plasticity of disgust. Evolution and Human Behavior, 27, 357-365.

848 doi:10.1016/j.evolhumbehav.2006.03.003

849 Case, K. L., Laubacher, M. C., Olausson, H., Binquan, W., Spagnolo, P. A., \& Bushnell, M.

850 C. (2016). Encoding of touch intensity but not pleasantness in human primary

851 somatosensory cortex. The Journal of Neuroscience, 36, 5850-5860.

852 doi:10.1523/JNEUROSCI.1130-15.2016.

853 Chapman, H. A., \& Anderson, A. K. (2013). Things rank and gross in nature: A review and 854 synthesis of moral disgust. Psychological Bulletin, 139, 300-327.

$855 \quad$ doi: $10.1037 / \mathrm{a} 0030964$

856 Chappuis, C. J., Niclass, Y., Cayeux, I., \& Starkenmann, C. (2015). Sensory survey of key

857 compounds of toilet malodour in Switzerland, India and Africa. Flavour and

$858 \quad$ Fragrance Journal, 31, 95-100. doi.org/10.1002/ffj.3293

859 Coen, S. J., Gregory, L. J., Yágüez, L., Amaro, E, Jr., Brammer, M., Williams, S. CR., \&

860 Aziz, Q. (2007). Reproducibility of human brain activity evoked by esophageal

861 stimulation using functional magnetic resonance imaging. American Journal of

862 Physiology, 293, G188-197. doi:10.1152/ajpgi.00461.2006.

863 Cottrell, C. A., \& Neuberg, S. L. (2005) Different emotional reactions to different groups: a

864 sociofunctional threat-based approach to "prejudice". Journal of Personality and

$865 \quad$ Social Psychology, 88, 770-789. doi:10.1037/0022-3514.88.5.77.

866 Coulthard, H., \& Sahota, S. (2016). Food neophobia and enjoyment of tactile play:

867 Associations between preschool children and their parents. Appetite, 97, 155-159.

868 doi:10.1016/j.appet.2015.11.028 
869 Craig, A. D. (2003) Interoception: The sense of the physiological condition of the 870 body. Current Opinion in Neurobiology, 13, 500-505. doi:10.1016/S09594388(03)00090-4.

872 Curtis, V., \& Biran, A. (2001). Dirt, disgust, and disease. Is hygiene in our genes? Perspectives in Biology and Medicine, 44, 17-31. doi:10.1353/pbm.2001.0001.

874 Darwin, C. (1872/1998). The expression of emotion in man and animals. Project Gutenberg 875 EBook \#1227.

Davey, G. C. L. (1994) Disgust. In: Encyclopaedia of Human Behavior, (ed) V. Ramachandran, [pp. 135-143]. Academic Press.

878 De Silva, P., \& Rachman, S. (1987). Human food aversions: Nature and acquisition. 879 Behaviour Research and Therapy, 25, 457-468. doi:10.1016/0005-7967(87)90053-2.

880 Decety, J., \& Grèzes, J. (2006). The power of simulation: Imagining one's own and other's 881 behavior. Brain Research, 1079, 4-14. doi: 10.1016/j.brainres.2005.12.115.

882 de Jong, P., Van Overveld, M. \& Borg, C. (2013). Giving in to arousal or staying stuck in 883 disgust? Disgust-based mechanisms in sex and sexual dysfunction. Journal of Sex $884 \quad$ Research, 5, 247-262.

885 de Wijk, R. A., Polet, I. A., Engelen, L., van Doorn, R. M., \& Prinz, J. F. (2004). Amount of 886 887 ingested custard dessert as affected by its color, odor, and texture. Physiology \& Behaviour, 82, 397-403. doi:1016/j.physbeh.2004.04.053.

888 Ekman, P. (1999). Basic emotions. In: Handbook of Cognition and Emotion (pp. 45-60). John 889 Wiley.

890 Engen T. (1988) The acquisition of odour hedonics. In: Perfumery: The Psychology and 891 Biology of Fragrance, (eds) S. Van Toller \& G. H. Dodd [pp.79-90]. Chapman $892 \quad$ and Hall.

893 Fairbrother, N., Newth, S. J., \& Rachman, S. (2005). Mental pollution: Feelings of 

dirtiness without physical contact. Behaviour Research and Therapy, 43, 121-130. doi:10.1016/j.brat.2003.12.005.

896 Fairhurst, M., Fairhurst, K., Berna, C., \& Tracey, I. (2012). An fMRI study exploring the 897 898 overlap and differences between neural representations of physical pain. PLoS One, 7, 1-10. doi:10.1371/journal.pone.0048711

899 Fan, Q. \& Olatunji, B.O. (2013). Individual differences in disgust sensitivity and health $900 \quad$ related avoidance: Examination of specific associations. Personality and Individual 901 Differences, 55, 454-458. doi:10.1016/j.paid.2013.04.007

902 Fessler, D. M. T., \& Hayley, K. J. (2006). Guarding the perimeter: The outside-inside 903 dichotomy in disgust and bodily experience. Cognition and Emotion, 20, 3-19. $904 \quad$ doi:10.1080/02699930500215181.

905 Fleischman, D. S., \& Fessler, D. MT. (2011). Progesterone's effects on the psychology 906 of disease avoidance: Support for the compensatory behavioral prophylaxis 907 hypothesis. Hormones and Behavior, 59, 271-275. doi:10.1016/j.yhbeh.2010.11.014.

909 Ganchrow, J. R., Steiner, J. E., \& Daher, M. (1983). Neonatal facial expressions in response 910 to different qualities and intensities of gustatory stimuli. Infant Behavior and 911 Development, 6, 473-484. doi:10.1016/s0163-6383(83)90301-6

912 Garcia, J., \& A. Koelling, R. (1966) Relation of cue to consequence in avoidance learning. 913 Psychonomic Science, 4, 123-124. doi:10.3758/BF03342209.

914 Gerrards-Hesse, A., Spies, K. \& Hesse, F. (1994). Experimental inductions of emotional 915 states and their effectiveness: A review. British Journal of Psychology, 85, 55-78. 916 Giner-Sorolla, R., \& Chapman, H. A. (2013). Beyond purity: Moral disgust toward bad 917 character. Psychological Science, 28, 1-12. doi:10.1177/0956797616673193.

918 Glendinning, J. (2007). How do predators cope with chemically defended foods? Biological 
920 Green, B. G. (2002). Studying taste as a cutaneous sense. Food Quality and Preference, 14, 99-109. doi:10.1016/S0950-3293(02)00071-X

922 Greer, M. J., \& Capecchi, M. R. (2002). Hoxb8 is required for normal grooming behaviour in 923 mice. Neuron, 33, 23-34. doi:10.1016/S0896-6273(01)00564-5.

924 Guinard, J-X., \& Mazzucchelli, R. (1996). The sensory perception of texture and mouthfeel. 925 Trends in Food Science and Technology, 7, 213-219. doi:10.1016/0924926 2244(96)10025-X.

927 Gustafsson, E., Jalme, M. S., Bomsel, M. C., \& Krief, S. (2014). Food neophobia and social 928 learning opportunities in great apes. International Journal of Primatology, 35, 1037929 1071. doi:10.1007/s10764-014-9796-y

930 Haase, L., Cerf-Ducastel, B., \& Murphy, C. (2009). Cortical activation in response to pure 931 taste stimuli during the physiological states of hunger and satiety. NeuroImage, 44, 932 1008-1021. doi:10.1016/j.neuroimage.2008.09.044.

933 Haddad, R., Medhanie, A., Roth, Y., Harel, D., \& Sobel, N. (2010). Predicting odor 934 pleasantness with an electronic nose. PLoS Computational Biology, 6, 1-11. 935 doi:10.1371/journal.pcbi.1000740

936 Haidt, J., McCauley, C., \& Rozin, P. (1994). Individual differences in sensitivity to disgust: 937 A scale sampling seven domains of disgust elicitors. Personality and Individual 938 Differences, 16, 701-713. doi:10.1016/0191-8869(94)90212-7

939 Han, D., Kollareth, D., \& Russell, J. (2016). The words for disgust in English, Korean, and $940 \quad$ Malayalam question its homogeneity. Journal of Language and Social $941 \quad$ Psychology, 35, 569-588. doi:10.1177/0261927x15619199

942 Heath, C., Bell, C. \& Sternberg, E. (2001). Emotional selection in memes: The case of urban 943 legends. Journal of Personality and Social Psychology, 81, 1028-1041. 
944 Hemenover, S. H., \& Schimmack, U. (2007). That's disgusting! ..., but very amusing: Mixed

945 feelings of amusement and disgust. Cognition and Emotion, 21, 1102-1113.

946 doi:10.1080/02699930601057037.

947 Herz, R. S. (2011). PROP taste sensitivity is related to visceral but not moral

948 disgust. Chemosensory Perception, 4, 72-79. doi:10.1007/s12078-011-9089-1.

949 Herz, R. S. \& von Clef, J. (2001). The influence of verbal labelling on the perception of

$950 \quad$ odors: Evidence for olfactory illusions? Perception, 30, 381-391.

951 Hesslow, G. (2002). Conscious thought as simulation of behaviour and perception. Trends in $952 \quad$ Cognitive Sciences, 6, 242-247.

953 Hoefling, A., Likowski, K., Deutsch, R., Hafner, M., Seibt, B., Muhlberger, A., Weyers, P. \& 954 Strack, F. (2009). When hunger finds no fault with moldy corn: Food deprivation 955 reduces food-related disgust. Emotion, 9, 50-58.

956 Izard, C. E. (2007). Basic emotions, natural kinds, emotion schemas, and a new paradigm.

957 Perspectives on Psychological Science, 2, 260-280. doi:10.1111/j.1745-

$958 \quad$ 6916.2007.00044.x.

959 Jackson, P., Rainville, P., \& Decety, J. (2006). To what extent do we share the pain of others?

960 Insight from the neural bases of pain empathy. Pain, 125, 5-9.

961 doi:10.1016/j.pain.2006.09.013.

962 Jackson, T., Wang, Y. \& Fan, H. (2014). Associations between pain appraisals and pain

963 outcomes: Meta-analysis of laboratory pain and chronic pain literature. Journal of

964 Pain, 15, 558-601. doi: 10.1016/j.pain.2014.01.499

965 Jabbi, M., Bastiaansen, J., \& Keysers, C. (2008). A common anterior insula representation of

966 disgust observation, experience and imagination shows divergent functional

967 connectivity pathways. PLoS One, 3, 1-8. doi: 10.1371/journal.pone.0002939

968 Kaerts, N., Van Hal, G., Vermandel, A., \& Wyndaele, J. J. (2012). Readiness signs used to 
969 define the proper moment to start toilet training. A review of the literature.

$970 \quad$ Neurourology and Urodynamics, 31, 437-440. doi: 10.1002/nau.21211

971 Kamiya, A., \& Ose, Y. (1984). Study of odorous compounds produced by the putrefaction of 972 food: V. Fatty acids, sulphur compounds and amines. Journal of Chromotography, 973 292, 383-391. doi:10.1016/S0021-9673(01)83617-7.

974 Keller, A., Gerkin, R. C., Guan, Y., Dhurandhar, A., Turu, G., Szalai, B., ... Meyer, P. 975 (2017). Predicting human olfactory perception from chemical features of odor 976 molecules. Science, 355, 820-826. doi:10.1126/science.aal2014.

977 Kendler, K. S., Myers, J., Prescott, C. A., \& Neale, M. C. (2001). The genetic epidemiology 978 of irrational fears and phobias in men. Archives of General Psychiatry, 58, 257-265. 979 doi:10.1001/archpsyc.58.3.257.

980 Kermen, F., Chakirian, A., Sezille, C., Joussain, P., Le Goff, G., Ziessel, A., ... Bensafi, M. 981 (2011). Molecular complexity determines the number of olfactory notes and the 982 pleasantness of smells. Scientific Reports, 206, doi:10.1038/srep00206.

983 Khan, R. M., Luk, C. H., Flinker, A., Aggarwal, A., Lapid, H., Haddad, R., \& Sobel, N. 984 (2007). Predicting odor pleasantness from odorant structure: pleasantness as a 985 reflection of the physical world. Journal of Neuroscience, 27, 10015-10023. 986 doi:10.1523/jneurosci.1158-07.2007.

987 Kim, L. R., \& Kim, N. S. (2011). A proximity effect in adults' contamination intuitions. $988 \quad$ Judgement and Decision Making, 6, 222-229.

989 Kollareth, D., \& Russell, J. A. (2016). Is it disgusting to be reminded that you are an $990 \quad$ animal? Cognition and Emotion, 19, 1-15. doi:10.1080/02699931.2016.1221382

991 Koteles, F. \& Witthoft, M. (2017) Somatosensory amplification - an old construct from a new 992 perspective. Journal of Psychosomatic Research, 101, 1-9.

993 doi:10.1016/j.jpsychores.2017.07.011 
994 Krolak-Salmon, P., Hénaff, M. A., Isnard, J., Tallon-Baudry, C., Guénot, M., Vighetto, A., 995 ... Mauguière, F. (2003). An attention modulated response to disgust in human 996 ventral anterior insula. Annals of Neurology, 53, 446-453. doi:10.1002/ana.10502.

997 Kupfer, T. R. (2018). Why are injuries disgusting? Comparing pathogen avoidance and 998 empathy accounts. Emotion, 18, 959-970.

999 Lamm, C., Decety, J., \& Singer, T. (2011). Meta-analytic evidence for common and distinct 1000 neural networks associated with directly experienced pain and empathy for pain. $1001 \quad$ Neuroimage, 54, 2492-2502. doi:10.1016/j.neuroimage.2010.10.014

1002 Lane, R. D., Reiman, E. M., Bradley, M. M., Lang, P. L., Ahern, G. L., Davidson, R. J., \& 1003 Schwartz, G. E. (1997). Neuroanatomical correlates of pleasant and unpleasant 1004 emotion. Neuropsychologia, 35, 1437-1444. doi:10.1016/S0028-3932(97)00070-5.

1005 Laska, M., Bautista, R. M., Hofelmann, D., Sterlemann, V., \& Salazar, L. T. (2007) Olfactory

1006 sensitivity for putrefaction-associated thiols and indoles in three species of non1007 human primate. Journal of Experimental Biology, 210, 4169-4178.

$1008 \quad$ doi:10.1242/jeb.012237

1009 Loewenstein, G., Weber, E., Hsee, C. \& Welch, N. (2001). Risk as feelings. Psychological $1010 \quad$ Bulletin, 127, 267-286. doi 10.1037//0033-2909.127.2.267

1011 Logue, A. W., Ophir, I., \& Strauss, K. E. (1981). The acquisition of taste aversions in 1012 humans. Behaviour Research and Therapy, 19, 319-333. doi:10.1016/0005$1013 \quad 7967(81) 90053-X$

1014 Martins, Y., \& Pliner, P. (2005). Human food choices: An examination of the factors 1015 underlying acceptance/rejection of novel and familiar animal and nonanimal foods. $1016 \quad$ Appetite, 45, 214-224. doi:10.1016/j.appet.2005.08.002

1017 Martins, Y., \& Pliner, P. (2006). “Ugh! That's disgusting!": Identification of the 1018 characteristics of foods underlying rejections based on disgust. Appetite, 46, 75-85. 
1019 doi:10.1016/j.appet.2005.09.001

1020 Marzillier, S., \& Davey, G. (2004). The emotional profiling of disgust eliciting stimuli:

1021 Evidence for primary and complex disgusts. Cognition and Emotion, 18, 313-336.

1022 doi:10.1080/02699930341000130

1023 Mizrahi, A. (2018). The hard and soft wired nature of the olfactory map. Trends in

1024 Neurosciences, 41, 872-874. doi:10.1016/j.tins.2018.06.007

1025 Moll, J., Oliveira-Souza, R. D., Moll, F. T., Fátima. I. A., Ivanei, B. E., Caparelli-Dáquer, E.

1026 M., \& Eslinger, P. (2005). The moral affiliations of disgust. A functional MRI study.

1027 Cognitive and Behavioural Neurology, 18, 68-78.

1028 doi:10.1097/01.wnn.0000152236.46475.a7.

1029 Moncrieff, R. W. (1966). Odour Preferences. Leonard Hill

1030 Morton, D. L., Sandhu, J. S., \& Jones, A. K. (2016). Brain imaging of pain: State of the art.

1031 Journal of Pain Research, 9, 613-624. doi:10.2147/JPR.S60433.

1032 Muris, P., Mayer, B., Maraike, B., \& Maruschka, V. (2013). Nonverbal and verbal

1033 transmission of disgust from mothers to offspring: Effects on children's evaluation of

1034 a novel animal. Behaviour Therapy, 44, 293-301. doi:10.1016/j.beth.2012.10.002.

1035 Nabi, R. L. (2002). The theoretical versus the lay meaning of disgust: Implications for

1036 emotion research. Cognition and Emotion, 16, 695-703.

1037 doi:10.1080/02699930143000437.

1038 Napadow, V., Sheehan, J. D., Kim, J., LaCount, L. T., Park, K., Rosen, B. R. \& Kuo, B.

1039 (2013). The brain circuitry underlying the temporal evolution of nausea in humans.

$1040 \quad$ Cerebral Cortex, 23, 806-813. doi:10.1093/cercor.bhs073.

1041 Nederkoon, C., Jansen, A., \& Havermans, R. C. (2015). Feel your food. The influence of

1042 tactile sensitivity on picky eating in children. Appetite, 84, 7-10.

$1043 \quad$ doi:10.1016/j.appet.2014.09.014. 
1044 Nordin, S., Broman, D. A., Garvill, J., \& Nyroos, M. (2004). Gender differences in factors 1045 affecting rejection of food in healthy young Swedish adults. Appetite, 43, 295-301. 1046 doi:10.1016/j.appet.2004.07.002.

1047 Oaten, M., Stevenson, R. J., \& Case, T. I. (2009). Disgust as a disease-avoidance 1048 mechanism. Psychological Bulletin, 135, 303-321. doi:10.1037/a0014823.

1049 Oatley, K. (2016). Fiction: Simulation of social worlds. Trends in Cognitive Sciences, 20, 1050 618-628. doi:10.1016/j.tics.2016.06.002.

1051 Ogino, Y., Nemoto, H., Inui, K., Saito, S., Kakigi, R., \& Goto, F. (2007). Inner experience of 1052 pain: Imagination of pain while viewing images showing painful events forms 1053 subjective pain representation in human brain. Cerebral Cortex, 17, 1139-1146. 1054 doi:10.1093/cercor/bhl023.

1055 Olatunji, B. O., Adams, T., Ciesielski, B., David, B., Sarawgi, S., \& Broman-Fulks, J. (2012). 1056 The three domains of disgust scale: factor structure, psychometric properties, and 1057 conceptual limitations. Assessment, 19, 205-225. doi:10.1177/1073191111432881. 1058 Olatunji, B. O., Haidt, J., McKay, D., \& David, B. (2008). Core, animal reminder, and 1059 contamination disgust: Three kinds of disgust with distinct personality, behavioral, $1060 \quad$ physiological, and clinical correlates. Journal of Research in Personality, 42, 12431061 1259. doi:10.1016/j.jrp.2008.03.009

1062 Olatunji, B. O., Moretz, M. W., McKay, D., Bjorklund, F., de Jong, P. J., \& Haidt, J., ... 1063 Schienle, A. (2009). Confirming the three-factor structure of the disgust scale1064 Revised in eight countries. Journal of Cross-Cultural Psychology, 40, 234-255. $1065 \quad$ doi: $10.1177 / 0022022108328918$

1066 Ortony, A., \& Turner, T. J. (1990). What's basic about basic emotions? Psychological 1067 Review, 97, 315-331. doi:10.1037/0033-295X.97.3.315

1068 Ottaviani, C., Mancini, F., Petrocchi, N., Medea, B., \& Couyoumdjian, A. (2013). 
Autonomic correlates of physical and moral disgust. International Journal of Psychophysiology, 89, 57-62. doi:10.1016/j.ijpsycho.2013.05.003.

1071 Oum, R. E., Lieberman, D., \& Aylward, A. (2011). A feel for disgust: tactile cues to 1072 pathogen presence. Cognition and Emotion, 25, 717-725.

1073 doi:10.1080/02699931.2010.496997

1074 Page, A. C. (1994). Blood-injury phobia. Clinical Psychological Review, 14, 443-461. 1075 doi:10.1016/0272-7358(94)90036-1

1076 Paradiso, S., Johnson, D. L., Andreasen, N. C., O'Leary, D. S., Arndt, S., Cizadlo, T., Ponto 1077 L. L. B., ... Hichwa, R. D. (1997). Left amygdala and prefrontal activation during 1078 conscious evaluation of emotional valence of visual stimuli. NeuroImage, 5, 1-16. 1079 doi:10.1038/srep25826.

1080 Penfield, W., \& Faulk, M. E. (1955). The insula: Further observations on its function. Brain, $1081 \quad 78,445-470$. doi:10.1093/brain/78.4.445.

1082 Peng, Y., Smith, S. G., Jin, H., Tränkner, D., Ryba, N. J. P., \& Zuker, C. S. (2015). Sweet 1083 and bitter taste in the brain of awake behaving animals. Nature, 527, 512-515. 1084 doi:10.1038/nature15763.

1085 Ploghaus, K., Tracey, I., Gati, J. S., Clare, S., Menon, S. R., Matthews, P. M., \& Rawlins, J. 1086 N. (1999). Dissociating pain from its anticipation in the human brain. Science, 284, 979-1981. doi:10.1126/science.284.5422.1979

1088 Poncelet, J., Rinck, F., Ziessel, A., Joussain, P., Thévenet, M., Rouby, C., \& Bensafi, M. 1089 (2010). Semantic knowledge influences prewired hedonic responses to odors. PLoS $1090 \quad$ One, 5, 1-8. doi:10.1371/journal.pone.0013878

1091 Rachman, S. (2006). Fear of Contamination: Assessment and Treatment. Oxford University $1092 \quad$ Press.

1093 Ramirez, I. (1992). Malaise can condition avoidance of high velocity fluids. Physiology \& 
1094

1095

1096

1097

1098

1099

1100

1101

1102

1103

1104

1105

1106

1107

1108

1109

1110

1111

1112

1113

1114

1115

1116

1117

1118

Behaviour, 52, 929-934. doi:10.1016/0031-9384(92)90373-A.

Riskind, J. H., \& Maddux, J. E. (1994). Loomingness and the fear of AIDS: Perceptions of motion and menace. Journal of Applied Social Psychology, 24, 432-442. doi:10.1111/j.1559-1816.1994.tb00591.x.

Robinson, B. W., \& Mishkin, M. (1968). Alimentary responses to forebrain stimulation in monkeys. Experimental Brain Research, 4, 330-366.

Rolls, E. T., Kringelbach, M. L., \& De Araujo, I. E. (2003). Different representations of pleasant and unpleasant odours in the human brain. European Journal of Neuroscience, 18, 695-703. doi:10.1046/j.1460-9568.2003.02779.x.

Royzman, E. B., \& Sabini, J. (2001). Something it takes to be an emotion: The interesting case of disgust. Journal for the Theory of Social Behaviour, 31, 29-59. doi:10.1111/1468-5914.00145

Royzman, E., Atanasov, P., Landy, J. F., Parks, A., \& Gepty, A. (2014). CAD or MAD? Anger (not disgust) as the predominant response to pathogen-free violations of the divinity code. Emotion, 14, 892-907.

Royzman, E. B., Leeman, R. F., \& Sabini, J. (2008). "You make me sick": Moral dyspepsia as a reaction to third-party sibling incest. Motivation \& Emotion, 32, 100-108.

Rozin, P. (1976a) Psychobiological and cultural determinants of food choice. Dahlem Workshop on Appetite and Food Intake, (ed) T. Silverstone, [pp 285-312]. Dahlem Konferenzen.

Rozin, P. (1976b). The selection of foods by rats, humans and other animals. Advances in the Study of Behavior, 6, 21-76.

Rozin, P. (2008). Specific habituation to disgust/death elicitors as a result of dissecting a cadaver. Judgment and Decision Making, 3, 191-194. 
1119 magical law of contagion in interpersonal attitudes among Americans. Bulletin of the $1120 \quad$ Psychonomic Society, 27, 367-370. doi.org/10.3758/BF03334630.

1121 Rozin, P., \& Fallon, A. (1987). A perspective on disgust. Psychological Review, 94, 23-41. 1122 doi:10.1037//0033-295X.94.1.23

1123 Rozin, P., Markwith, M., \& McCauley, C. (1994). Sensitivity to indirect contacts with other 1124 person: AIDS aversion as a composite of aversion to strangers, infection, moral taint 1125 and misfortune. Journal of Abnormal Psychology, 103, 495-504. doi:10.1037/0021$1126 \quad$ 843X.103.3.495.

1127 Rozin, P., Millman, L., \& Nemeroff, C. (1986). Operation of the laws of sympathetic magic 1128 in disgust and other domains. Journal of Personality and Social Psychology, 50, 7031129 712. doi:10.1037/0022-3514.50.4.703

1130 Rozin, P., Fallon, A., \& Augustoni-Ziskind, M. (1985). The child's conception of food: The 1131 development of contamination sensitivity to "disgusting" substances. Developmental 1132 Psychology, 21, 1075-1079. doi:10.1037/0012-1649.21.6.1075.

1133 Rozin, P., Haidt, J., \& Fincher, K. (2009). From oral to moral. Science, 323, 1179-1180. 1134 doi:10.1126/science.1170492.

1135 Rozin, P., Haidt, J., \& McCauley, R. C. (2016). Disgust. In: Handbook of Emotions (eds) L. 1136 F. Barrett., Lewis, M \& Haviland-Jones, J. M, [pp.815-834]. Guilford Press.

1137 Rozin, P., Haidt, J., McCauley, C., Dunlop, L., \& Ashmore, M. (1999). Individual differences 1138 in disgust sensitivity: Comparisons and evaluations of paper-and-pencil versus 1139 behavioral measures. Journal of Research in Personality, 33, 330-351. $1140 \quad$ doi:10.1006/jrpe.1999.2251

1141 Rozin, P., Lowery, L., \& Ebert, R. (1994). Varieties of disgust faces and the structure of 1142 disgust. Journal of Personality and Social Psychology, 66, 870-881.

1143 doi:10.1037//0022-3514.66.5.870 
1144 Rozin, P., \& Nemeroff, C. (1990). The laws of sympathetic magic: A psychological analysis 1145 of similarity and contagion. In: Cultural psychology: Essays on comparative human 1146 development, (eds) J. W. Stigler, R. A. Shweder \& G. Herdt, [pp. 205-232]. 1147 Cambridge University Press.

1148 Rozin, P., Nemeroff, C., Horowitz, M., Gordon, B., \& Voet, W. (1995). The borders of the 1149 self: Contamination sensitivity and potency of the body apertures and other body $1150 \quad$ parts. Journal of Research in Personality, 29, 318-340. doi:10.1006/jrpe.1995.101 1151 Russell, C. G., \& Worsley, A. (2013). Why don't they like that? And can I do anything about 1152 it? The nature and correlates of parents' attributions and self-efficacy beliefs about 1153 preschool children's food preferences. Appetite, 66, 34-43. $1154 \quad$ doi:10.1016/j.appet.2013.02.020

1155 Sachs, D. B. (1988). The development of grooming and its expression in adult animals. 1156 Annals of the New York Academy of Science, 525, 1-17. doi:10.1111/j.17491157 6632.1988.tb38591.x.

1158 Sacco, D. F., Young, S. G., \& Hugenberg, K. (2014). Balancing competing motives: 1159 Adaptive trade-offs are necessary to satisfy disease avoidance and interpersonal $1160 \quad$ affiliation goals. Personality \& Social Psychology Bulletin, 40, 1611-1623.

1161 Sarabian, C., Ngoubangoye, B., \& MacIntosh, A. J. J. (2017). Avoidance of biological 1162 contaminants through sight, smell and touch in chimpanzees. Royal Society Open $1163 \quad$ Science, 4, 1-11. doi:10.1098/rsos.170968.

1164 Sawchuk, C. N., Lohr, J. M., Westendorf, D. H., Meunier, S. A., \& Tolin, D. F. (2002). 1165 Emotional responding to fearful and disgusting stimuli in specific phobics. Behavior 1166 Research and Therapy, 40, 1031-1046. doi:10.1016/S0005-7967(01)00093-6

1167 Scarantino, A. (2012). How to define emotions scientifically. Emotion Review, 4, 358-368. 1168 doi:10.1177/1754073912445810. 
1169 Schafer, A., Schienle, A., \& Vaitl, D. (2005). Stimulus type and design influence

1170 hemodynamic response towards visual disgust and fear elicitors. International

1171 Journal of Psychophysiology, 57, 53-59. doi:10.1016/j.iipsycho.2005.01.011.

1172 Schienle, A., Arendasy, M. \& Schwab, D. (2015). Disgust responses to bitter compounds:

1173 The role of disgust sensitivity. Chemosensory Perception, 8, 167-173.

1174 doi:10.1007/s12078-015-9186-7

1175 Schienle, A., Stark, R., Walter, B., Blecker, C., Ott, U., Kirsch, P., Sammer. G., \& Vaitl, D.

1176 (2002). The insula is not specifically involved in disgust processing: An fMRI study.

1177 NeuroReport, 13, 2023-2026. doi:10.1097/00001756-200211150-0000.

1178 Schienle, A., Schäfer, A., Stark, R., Walter, B., \& Vaitl, D. (2005). Gender differences in the 1179 processing of disgust- and fear-inducing pictures: An fMRI study. NeuroReport, 16, 1180 277-280. doi:10.1097/00001756-200502280-00015.

1181 Scott, T. R., \& Mark, G. P. (1987). The taste system encodes stimulus toxicity. Brain 1182 Research, 414, 197-203. doi:10.1016/0006-8993(87)91347-3.

1183 Seubert, J., Kellermann, T., Loughead, J., Boers, F., Brensinger, C., Schneider, F., \& Habel, 1184 U. (2010). Processing of disgusted faces is facilitated by odor primes: A functional 1185 MRI study. NeuroImage, 53, 746-756. doi:10.1016/j.neuroimage.2010.07.012.

1186 Shenhav, A., \& Mendes, W. B. (2014). Aiming for the stomach and hitting the heart:

1187 Dissociable triggers and sources for disgust reactions. Emotion, 14, 301-309

1188 Simpson, J., Carter, S., Anthony, S. H., \& Overton, P. G. (2006). Is disgust a homogeneous 1189 emotion? Motivation and Emotion, 30, 31-41. doi:10.1007/s11031-006-9005-1

1190 Singer, T., \& Lamm, C. (2009). The social neuroscience of empathy. Annals of the New York $1191 \quad$ Academy of Sciences, 1156, 81-96. doi:10.7551/mitpress/9780262012973.001.0001

1192 Skolnick, A. J. (2013). Gender differences when touching something gross: Unpleasant? No. 1193 disgusting? Yes! Journal of General Psychology, 140, 144-157. 
doi:10.1080/00221309.2013.781989

1195 Small, D. M., Gregory, M. D., Mak, Y. E., Gitelman, D., Mesulam, M. M., Parrish, T.

1196 (2003). Dissociation of neural representation of intensity and affective valuation in 1197 human gustation. Neuron, 39, 701-711. doi:10.1016/S0896-6273(03)00467-7.

1198 Soussignan, R., Schaal, B., Marlier, L., \& Jiang, T. (1997). Facial and autonomic responses

1199 to biological and artificial olfactory stimuli in human neonates: Re-examining early

1200 hedonic discrimination of odors. Physiology and Behavior, 62, 745-758.

$1201 \quad$ doi:10.1016/s0031-9384(97)00187-x

1202 Sparks, A. M., Fessler, D. M., Chan, K. Q., Ashokkumar, A., \& Holbrook, C. (2018). Disgust

1203 as a mechanism for decision making under risk: Illuminating sex differences and

1204 individual risk-taking correlates of disgust propensity. Emotion, 18, 942-958.

1205 Stark, R., Schienle, A., Walter, B., Kirsch, P., Sammer, G., Ott, U., Blecker, C., \& Vaitl, D.

1206 (2003). Hemodynamic responses to fear and disgust-inducing pictures: An fMRI

1207 study. International Journal of Psychophysiology, 50, 225-234. doi:10.1016/S0167-

$1208 \quad 8760(03) 00169-7$.

1209 Stark, R., Schienle, A., Sarlo, M., Palomba, D., Walter, B., \& Vaitl, D. (2005). Influences of

1210 disgust sensitivity on hemodynamic responses towards a disgust-inducing film clip.

1211 International Journal of Psychophysiology, 57, 61-67. doi:10.1016j-

$1212 \quad$ ijpsycho.2005.01.2010.

1213 Steiner, J. E. (1979). Human facial expressions in response to taste and smell stimulation.

1214 Advances in Child Development and Behavior, 13, 257-295. doi:10.1016/S0065-

$1215 \quad 2407(08) 60349-3$

1216 Steiner, J. E., Glaser, D., Hawilo, M. E., \& Berridge, K. C. (2001). Comparative expression

1217 of hedonic impact: Affective reactions to taste by human infants and other

1218 primates. Neuroscience \& Biobehavioral Reviews, 25, 53-74. doi:10.1016/s0149- 
1219

1220

1221

1222

1223

1224

1225

1226

1227

1228

1229

1230

1231

1232

1233

1234

1235

1236

1237

1238

1239

1240

1241

1242

1243

7634(00)00051-8

Stevenson, R.J. (2009). The Psychology of Flavour. Oxford University Press.

Stevenson, R. J. \& Case, T. I. (2005). Olfactory imagery: A review. Psychonomic Bulletin \& Review, 12, 244-264.

Stevenson, R. J., Case, T. I., \& Oaten, M. (2011). Effect of self-reported sexual arousal on responses to sex related and non-sex related disgust cues. Archives of Sexual Behavior, 40, 79-84.

Stevenson, R. J., Oaten, M., Case, T. I., Repacholi, B. M., \& Wagland, P. (2010). Children's response to adult disgust elicitors: Development and acquisition. Developmental Psychology, 46, 165-177.

Stevenson, R. J. (2014). Flavor binding: Its nature and cause. Psychological Bulletin, 140, 487-510.

Stevenson, R. J., Hodgson, D., Oaten, M. J., Moussavi, M., Langberg, R., Case, T. I., \& Barouei, J. (2012). Disgust elevates core body temperature and up-regulates certain oral immune markers. Brain, Behavior and Immunity, 26, 1160-1168. doi:10.1016/j.bbi.2012.07.010.

Stevenson, R. J., Hodgson, D., Oaten, M. J., Sominsky, L., Mahmut, M., \& Case, T. I. (2015). Oral immune activation by disgust and disease-related pictures. Journal of Psychophysiology, 29, 119-129. doi:10.1027/0269-8803/a000143.

Stevenson, R. J. \& Repacholi, B.M. (2005). Does the source of an interpersonal odour affect disgust? A disease risk model and its alternatives. European Journal of Social Psychology, 35, 375-401.

Tinbergen, N. (1963). On aims and methods of ethology. Zeitschrift fur Tierpsychologie, 20, $410-433$. 
1244

1245

1246

1247

1248

1249

1250

1251

1252

1253

1254

1255

1256

1257

1258

1259

1260

1261

1262

1263

1264

1265

1266

1267

1268

Physiology and Behavior, 50, 1027-1031. doi:10.1016/0031-9384(91)90432-N.

Tolin, D. F., Lohr, J. M., Sawchuk, C. N., \& Lee, T. C. (1997). Disgust and disgust sensitivity in blood-injection-injury and spider phobia. Behaviour Research and Therapy, 35, 949-953. doi:10.1016/S0005-7967(97)00048-X

Tucker, M., \& Bond, N. W. (1997). The roles of gender, sex role, and disgust in fear of animals. Personality and Individual Differences, 22, 135-138. doi:10.1016/S01918869(96)00168-7.

Tybur, J. M., Lieberman, D., \& Griskevicius, V. (2009). Microbes, mating, and morality: Individual differences in three functional domains of disgust. Journal of Personality and Social Psychology, 97, 103-122. doi:10.1037/a0015474

Tybur, J. M., Lieberman, D., Kurzban, R., \& DeScioli, P. (2013). Disgust: Evolved function and structure. Psychological Review, 120, 65-84. doi.org/10.1037/a0030778

Van Houtem, C. M., Laine, M. L., Boomsma, D. I., Ligthart, L., van Wijk, A. J., \& De Jongh, A. (2013). A review and meta-analysis of the heritability of specific phobia subtypes and corresponding fears. Journal of Anxiety Disorders, 27, 379-388. doi:10.1016/j.janxdis.2013.04.007

Verstaen A., Eckart, J. A., Muhtadie, L., Otero, M. C., Sturm, V. E., Haase, C. M., ... Levenson, R. W. (2016). Insular atrophy and diminished disgust reactivity. Emotion, 16, 903-912. doi:10.1037/emo0000195.

Vogt, B. A. (2005). Pain and emotion interactions in subregions of the cingulate gyrus. Nature Reviews Neuroscience, 6, 533-544. doi:10.1038/nrn1704.

von Bekesy, G. (1964). Olfactory analogue to directional hearing. Journal of Applied Physiology, 19, 363-373.

Ware, J., Jain, K., Burgess, I., \& Davey, G. C. (1994). Disease-avoidance model: Factor analysis of common animal fears. Behavior Research and Therapy, 32, 57-63. 
1269

1270

1271

1272

1273

1274

1275

1276

1277

1278

1279

1280

1281

1282

1283

1284

1285

1286

1287

1288

1289

1290

1291

1292

1293 doi:10.1016/0005-7967(94)90084-1

Weiland, R., Ellgring, H., \& Macht, M. (2010). Gustofacial and olfactofacial responses in human adults. Chemical Senses, 35, 841-853. doi:10.1093/chemse/bjq092

Wennig, R., Schneider, S., \& Meys, F. (2010). GC/MS based identification of skunk spray maliciously deployed as "biological weapon" to harm civilians. Journal of Chromatography B, 878, 1433-1436. doi:10.1016/j.jchromb.2009.10.032

Wicker, B., Keysers, C., Plailly, J., Royet, J. P., Gallese, V., \& Rizzolatti, G. (2003). Both of us disgusted in my insula: The common neural basis of seeing and feeling disgust. Neuron, 40, 655-664. doi:10.1016/S0896-6273(03)00679-2.

Widen, S. C., Pochedly, J. T., Pieloch, K., \& Russell, J. A. (2013). Introducing the sick face. Motivation and Emotion, 37, 550-557. doi:10.1007/s11031-013-9353-6

Wiech, K., Lin, C., Brodersen, K., Bingel, U., Ploner, M. \& Tracey, I. (2010). Anterior insula integrates information about salience into perceptual decisions about pain. Journal of Neuroscience, 30, 16324-16331. doi: 10.1523/jneurosci.2087-10.2010

Williams, A. (2002). Facial expression of pain: An evolutionary account. Behavioral and Brain Sciences, 25, 439-455.

Wright, P., He, G., Shapira, N. A., Goodman, W. K., \& Liu, Y. (2004). Disgust and the Insula: fMRI Responses to Pictures of Mutilation and Contamination. NeuroReport, 15, 2347-2351. doi:10.1097/00001756-200410250-00009.

Yeager, B. A., Huttly, S. R., Bartolini, R., Rojas, M., \& Lanata, C. F. (1999). Defecation practices of young children in a Peruvian shanty town. Social Science and Medicine, 49, 531-541. doi:10.1016/S0277-9536(99)00119-7

Yoder, A. M., Widen, S. C., \& Russell, J. A. (2016). The word disgust may refer to more than one emotion. Emotion, 16, 301-308. doi:10.1037/emo0000118

Zald, D. H., Hagen, M. C., \& Pardo, J. V. (2002). Neural correlates of tasting concentrated 
1294 quinine and sugar solutions. Journal of Neurophysiology, 87, 1063-1075. doi:

$1295 \quad 10.1152 /$ jn.00358.2001

1296 Zampini, M., \& Spence, C. (2004). The role of auditory cues in modulating the perceived

1297 crispness and staleness of potato chips. Journal of Sensory Studies, 19, 347-363.

1298 doi:10.1111/j.1745-459x.2004.080403.x.

1299 Zarzo, M. (2011). Hedonic judgments of chemical compounds are correlated with molecular

$1300 \quad$ size. Sensors, 11, 3667-3686. doi:10.3390/s110403667

1301 
1302 Table 1: Summary properties and features of the processes that generate disgust

1303

1304 Property and features

Disgust generation process

1305

(1)

(2)

24

(1)

.

1313

13

$\begin{array}{ll}2 & \\ 3 & 1 \\ 35 & \\ 6 & 1 \\ 7 & \\ 8 & 1 \\ 9 & \\ 0 & \\ 1 & \\ 2 & \\ 3 & \\ 4 & \\ 45 & \end{array}$

\begin{tabular}{llllll}
1306 & & & & & \\
\cline { 2 - 5 } \\
1307 & Eliciting stimulus present or absent when disgust occurs & Absent & Present & Present & Absent \\
1308 & Eliciting stimulus has discrete bodily location & Yes & Yes & No & No \\
1309 & Typical degree of bodily threat & Very high & High & Moderate & Low \\
1310 & Role of learning in generation process & None & None & Significant & Significant \\
1311 & Developmental appearance & Birth & Birth to toileting & Post-weaning & School age \\
1312 & Degree of intentional control over the disgust experience & Little & Some & Moderate & High \\
1313 & Related contamination process & CTA* & Explicit learning & Explicit learning & Imagined \\
1314 & Involvement of other emotions and states & None & None & Significant & Very significant \\
1315 & Occurrence in other mammals & Yes & Yes & Yes & No \\
1316 & & & & & \\
\hline
\end{tabular}

1317 *Conditioned taste aversion 
Figure 1: Cues to disgust, and the processing steps involved in generating the associated feeling state and contamination, with hashed lines and boxes indicating, respectively, pathways and processes involving a greater learning component

CUES

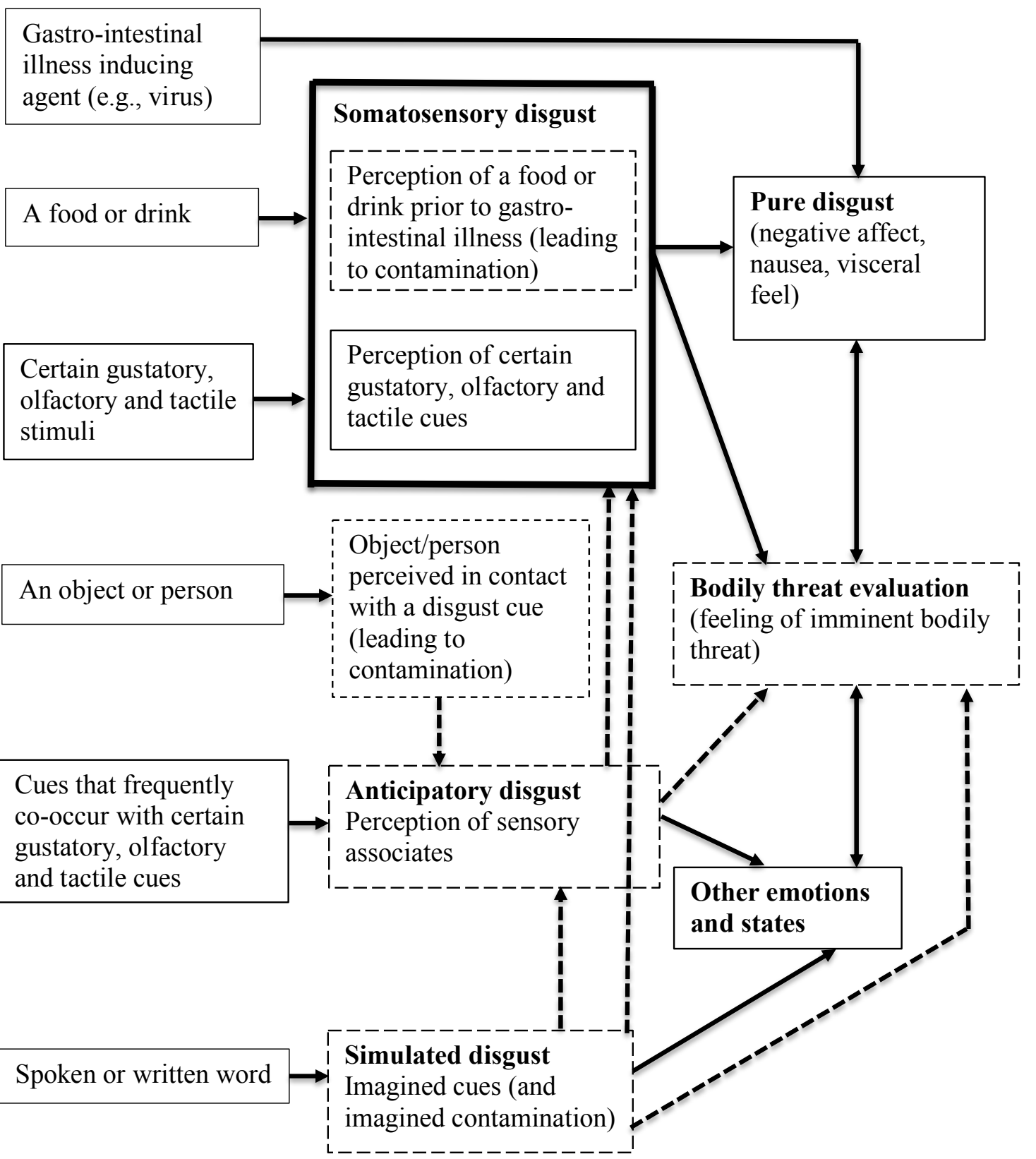

PROCESSING STEPS 